\title{
Facile synthesis of arabinomannose penta- and decasaccharide fragments of the lipoarabinomannan of the equine pathogen, Rhodococcus equi
}

\author{
Zuchao Ma, Jianjun Zhang and Fanzuo Kong* \\ Research Center for Eco-Environmental Sciences, Academia Sinica, PO Box 2871, Beijing 100085, PR China
}

Received 10 March 2004; accepted 15 April 2004

Available online 7 June 2004

\begin{abstract}
Pentasaccharide repeating unit $\mathbf{2 0}$ of the lipoarabinomannan from the equine pathogen, Rhodococcus equi, and its dimer 31, were synthesized. The pentasaccharide was obtained by assembling a benzoylated 2,6-branched mannosyl trisaccharide acceptor 13 with a free hydroxyl group at C-2' of the mannose residue attached to the core mannose residue by $(1 \rightarrow 6)$-linkage, followed by coupling with 2,3,5-tri- $O$-benzoyl- $\alpha$-D-arabinofuranosyl- $(1 \rightarrow 2)$-3,4,6-tri- $O$-benzoyl- $\alpha$-D-mannopyranosyl trichloroacetimidate $(\mathbf{1 8})$, and by deacylation. Meanwhile, the decamer 31 was obtained by firstly preparing a benzoylated mannose (1 $\rightarrow 6)$-linked tetrasaccharide backbone 26 with 2-, 2"-O-ClAc, and 2'-, 2"'-O-Ac groups, respectively, then by dechloroacetylation and subsequent condensation with perbenzoylated trichloroacetimidate, and then by deacetylation and subsequent coupling with $\mathbf{1 8}$, and finally, by deacylation.
\end{abstract}

(C) 2004 Elsevier Ltd. All rights reserved.

Keywords: Mannose; Arabinose; Regio- and stereoselective synthesis

\section{Introduction}

The equine pathogen, Rhodococcus equi, is a significant cause of disease in foals between the age of 1 and 5 months and is responsible for around 3\% of global foal mortality. ${ }^{1}$ This organism has also emerged as an opportunistic human pathogen, notably of people with compromised immunity. ${ }^{2} R$. equi is an intracellular pathogen of alveolar macrophages, a member of the mycolata, and its infection is characterized by bronchopneumonia. Members of the mycolata have a characteristic cell envelope that profoundly affects the properties of these bacteria, and its composition and organization have been a major focus of mycobacterial research. ${ }^{3}$ Lipoarabinomannan (LAM) is a complex mycobacterial cell envelope component that has been identified as a putative virulence factor of $M$. tubercu-

\footnotetext{
* Corresponding author. Tel.: +86-10-62936613; fax: +86-10-62923563; e-mail: fzkong@mail.rcees.ac.cn
}

losis $^{4}$ LAM has also been reported to have powerful immunomodulatory properties, promoting distinctive patterns of macrophages cytokine induction that subsequently directs host immune responses. ${ }^{5}$ Small differences in LAM structure can strongly influence these biological activities. The lipoglycan of $R$. equi has been isolated, purified, and characterized, ${ }^{6}$ and its structure is shown in Figure 1. It is composed of three domains. The first one is a polysaccharide consisting of a comb-like, 2-Man $p$ or -Araf-(1 $\rightarrow 2)$-Man $p$ branched six-linked mannose pentasaccharide repeating unit. The second one is a polysaccharide consisting of a mannose $(1 \rightarrow 6)$ linked disaccharide repeating unit, and the third one is the phosphatidyl-myo-inositol anchor attached with diacylated Man $p$. The synthesis of $(1 \rightarrow 6)$-linked mannose hexa-, octa-, and dodecasaccharide, corresponding to the structure of the second domain, has been reported by our group. ${ }^{7}$ We present herein the synthesis of the pentasaccharide repeating unit and its dimer, corresponding to the structure of the first domain of $R$. equi LAM. 


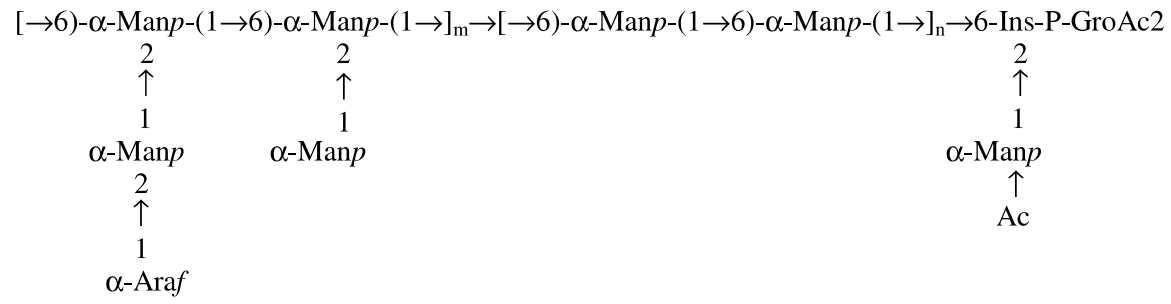

Figure 1. Structure of $R$. equi LAM.

\section{Results and discussion}

We have reported a method ${ }^{8}$ for mannose oligosaccharide syntheses using unprotected or lightly protected sugars as the glycosyl acceptors, and a variety of complex oligosaccharides have been synthesized efficiently. ${ }^{9}$ In the present research, a concise synthesis of the pentasaccharide repeating unit of the polysaccharide of $R$. equi LAM was achieved as shown in Scheme 1. Allyl 3$O$-benzoyl-4,6- $O$-benzylidene- $\alpha$-D-mannopyranoside (2) was chosen as the starting material that was prepared in high yield $(90.7 \%)$ by selective 3-O-benzoylation of allyl 4,6- $O$-benzylidene- $\alpha$-D-mannopyranoside (1) with benzoyl chloride in dichloromethane-pyridine. The ${ }^{1} \mathrm{H}$ NMR spectrum of $\mathbf{2}$ showed a characteristic doublet of doublets at $\delta 5.56$ with $J_{2,3}=3.2 \mathrm{~Hz}, J_{3,4}=10.3 \mathrm{~Hz}$ for $\mathrm{H}-3$, confirming the selectivity. Chloroacetylation of $\mathbf{2}$, followed by debenzylidenation, afforded the monosaccharide acceptor 3, while acetylation followed by debenzylidenation afforded the monosaccharide acceptor 4. Subsequent coupling of $\mathbf{3}$ with 2- $O$-acetyl-3,4,6-tri- $O$ benzoyl- $\alpha$-D-mannopyranosyl trichloroacetimidate (5) selectively gave the $(1 \rightarrow 6)$-linked disaccharide 6 $(86.4 \%)$, and the regioselectivity of the coupling was confirmed by benzoylation of $\mathbf{6}$ to give 7 that showed in its ${ }^{1} \mathrm{H}$ NMR spectrum a newly emerged signal at $\delta$ $5.93 \mathrm{ppm}$ with $J_{3,4}=J_{4,5}=10.1 \mathrm{~Hz}$ for $\mathrm{H}-4$ compared to 6. Dechloroacetylation of 7 afforded the disaccharide acceptor $\mathbf{8}$, while deallylation with $\mathrm{PdCl}_{2}{ }^{10}$ followed by trichloroacetimidate formation, ${ }^{11}$ yielded the disaccharide donor 10. Condensation of $\mathbf{8}$ with perbenzoylated mannosyl trichloroacetimidate $\mathbf{1 1}$ produced the trisaccharide $12(87.8 \%)$, and subsequent selective deacetylation ${ }^{12}$ with acetyl chloride in dichloromethane-methanol $(1: 5: 25 \mathrm{v} / \mathrm{v} / \mathrm{v})$ yielded the trisaccharide acceptor $\mathbf{1 3}$ in good yield (78.5\%). The other disaccharide block 18 was obtained through condensation of allyl 3,4,6-tri- $O$-benzoyl- $\alpha$-D-mannopyranoside (15) with perbenzoylated $\alpha$ D-arabinofuranosyl trichloroacetimidate $\mathbf{1 4}^{13}$ to afford the disaccharide 16 (87.2\%). Deallylation and subsequent trichloroacetimidate formation then produced the disaccharide donor $\mathbf{1 8}$ (77.7\% for two steps). Finally, condensation of $\mathbf{1 8}$ with the $\mathbf{1 3}$ gave pentasaccharide $\mathbf{1 9}$ $(81.5 \%)$, and deacylation in ammonia-saturated methanol yielded the pentasaccharide $20(91 \%)$. The ${ }^{1} \mathrm{H}$ and
${ }^{13} \mathrm{C}$ NMR spectra of $\mathbf{2 0}$ showed all of the characteristic signals such as at $\delta 5.06(\mathrm{~s}, 1 \mathrm{H}, \operatorname{Man} p \mathrm{H}-1), 5.05(\mathrm{~s}, 1 \mathrm{H}$, Araf $\mathrm{H}-1), 5.01$ (s, 1H, Manp H-1), 4.99 (s, 1H, Manp H-1), 4.89 (s, 1H, Man $p$ H-1); 109.36 (Araf C-1), 102.32, 101.36, 97.95, and 97.47 (Man $p$ C-1).

Decasaccharide 31, the dimer of the pentasaccharide repeating unit, was obtained in an alternative way. Thus, selective 6-O-glycosylation of 4 with the disaccharide donor $\mathbf{1 0}$ gave the trisaccharide 21 (84.5\%). Benzoylation of $\mathbf{2 1}$ produced 22, and its ${ }^{1} \mathrm{H}$ NMR spectrum showed a newly emerged signal at $\delta 5.92 \mathrm{ppm}$ with $J_{3,4}=J_{4,5}=9.9 \mathrm{~Hz}$ for $\mathrm{H}-4$ compared to $\mathbf{2 1}$, confirming the selective 6-O-glycosylation. Deallylation of 22, followed by trichloroacetimidate formation, gave the trisaccharide donor 24 (74.7\% for two steps). Subsequent selective coupling of the monosaccharide acceptor $\mathbf{3}$ with $\mathbf{2 4}$ yielded the tetrasaccharide $\mathbf{2 5}$ $(80.1 \%)$, and subsequent benzoylation gave the tetrasaccharide 26 with 2-, 2" -chloroacetyl, and 2'-, $2^{\prime \prime \prime}$-acetyl groups. The structure of $\mathbf{2 6}$ could allow different substitution at 2-, 2"'-, and 2'-, 2"'-positions. Thus, dechloroacetylation of $\mathbf{2 6}$ with thiourea produced tetrasaccharide acceptor $27(82.3 \%)$ with 2- and $2^{\prime \prime}$-free hydroxyl groups, and subsequent condensation with perbenzoylated mannosyl donor $\mathbf{1 1}$ gave the hexasaccharide $\mathbf{2 8}$ in high yield (85.9\%). Then, selective deacetylation under the same conditions as those used for deacetylation of $\mathbf{1 2}$ afforded the hexasaccharide acceptor $29(76.8 \%)$ with $2^{\prime}$ - and $2^{\prime \prime \prime}$-free hydroxyl groups. Finally, condensation of $\mathbf{2 9}$ with 18 (66.7\%), followed by deacylation, gave the target decasaccharide 31 (92.5\%). The ${ }^{1} \mathrm{H}$ and ${ }^{13} \mathrm{C}$ NMR spectra of $\mathbf{3 1}$ showed all of the characteristic signals such as at $\delta 5.09(\mathrm{~s}, 1 \mathrm{H}, \operatorname{Man} p \mathrm{H}-$ 1), 5.08 (s, 1H, Man $p \mathrm{H}-1), 5.07$ (s, 2H, Araf $2 \mathrm{H}-1), 5.02$ (s, 1H, Manp H-1), 5.01 (s, 1H, Manp H-1), 4.99 (s, 2H, Manp 2H-1), 4.93 (s, 1H, Manp H-1), 4.91 (s, 1H, Manp H-1); 109.36 (2C, Araf 2C-1), 102.32, 102.19, 101.32, 101.30, 98.17, 98.03, and 97.53 (8C, Manp 8C-1) (Scheme 2).

In summary, a facile synthesis of complex arabinomannosyl oligosaccharides was achieved through a regio- and stereoselective manner with readily accessible materials. The described method is suitable for preparation of a 2,6-branched comb-like mannan with arabinofuranose side chains. 

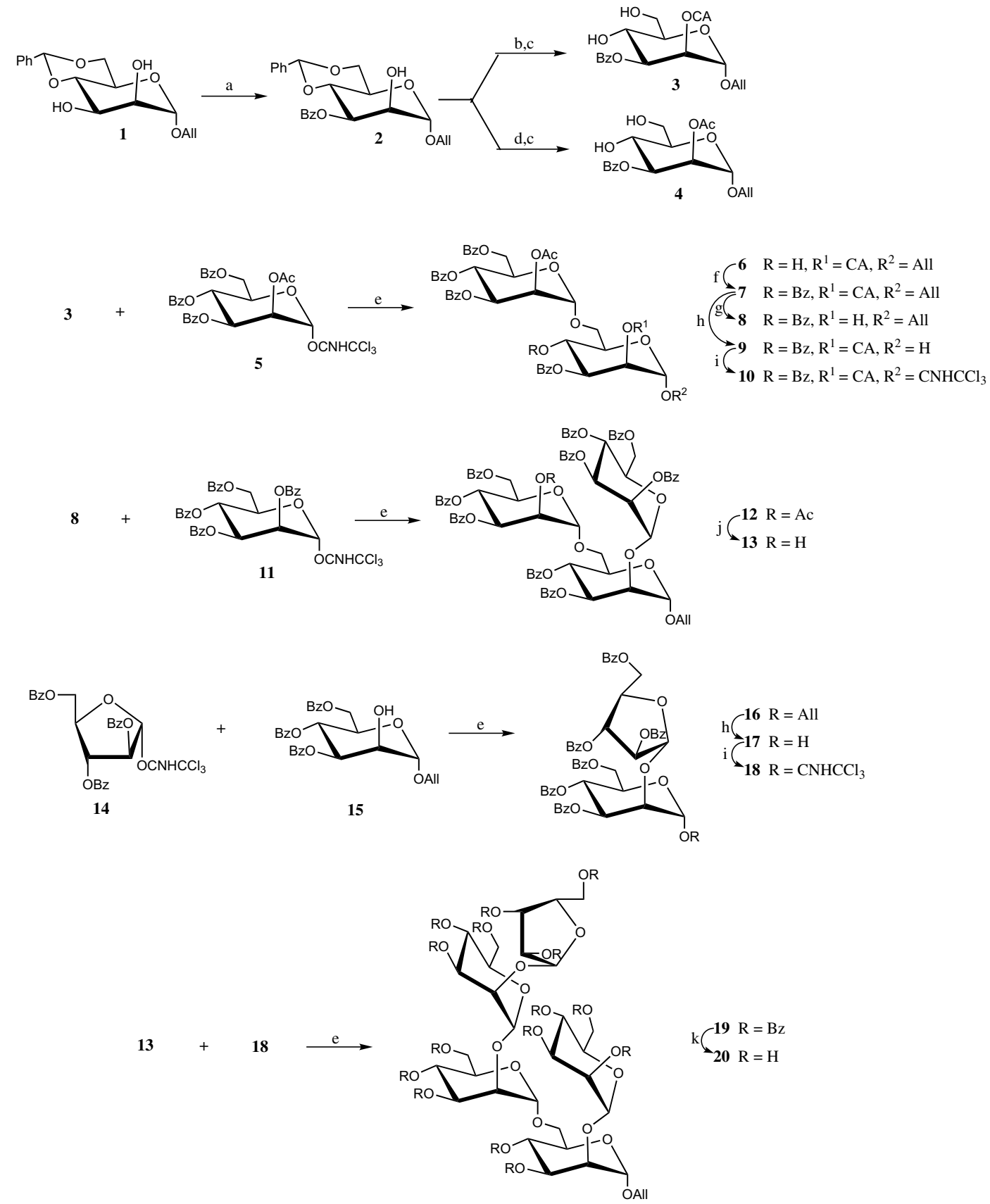

Scheme 1. Reagents and conditions: (a) $\mathrm{BzCl}, \mathrm{CH}_{2} \mathrm{Cl}_{2}$, pyridine, $90.7 \%$; (b), (c) $\mathrm{CH}_{2} \mathrm{ClCOCl}, \mathrm{CH}_{2} \mathrm{Cl}_{2}$, pyridine; $90 \%$ TFA, rt, $2 \mathrm{~h}$; $78.5 \%$ for two steps; (d), (c) $\mathrm{Ac}_{2} \mathrm{O}$-pyridine; $90 \%$ TFA, rt, $2 \mathrm{~h} ; 82.3 \%$ for two steps; (e) TMSOTf (0.01-0.05 equiv), $\mathrm{CH}_{2} \mathrm{Cl}_{2},-20$ to $0{ }^{\circ} \mathrm{C}, 2-4 \mathrm{~h}, 86.4 \%$ for $\mathbf{6}, 87.8 \%$ for $\mathbf{1 2}, 87.2 \%$ for $\mathbf{1 6}, 81.5 \%$ for $\mathbf{1 9}, 84.5 \%$ for $\mathbf{2 1}, 80.1 \%$ for $\mathbf{2 5}, 85.9 \%$ for $\mathbf{2 8}$, and $66.7 \%$ for $\mathbf{3 0}$, respectively; (f) BzCl-pyridine, $91.6 \%$ for $\mathbf{7}, 89.2 \%$ for 22, $85.5 \%$ for 26; (g) $\left(\mathrm{NH}_{2}\right)_{2} \mathrm{CS}, \mathrm{CH}_{2} \mathrm{Cl}_{2}-\mathrm{CH}_{3} \mathrm{OH}$, reflux, $16 \mathrm{~h}, 85.6 \%$ for $\mathbf{8}, 82.3 \%$ for $\mathbf{2 7}$; (h) $\mathrm{PdCl}_{2}, \mathrm{CH}_{3} \mathrm{OH}, \mathrm{rt}, 4 \mathrm{~h}, 84.5 \%$ for $\mathbf{9}, 82.4 \%$ for $\mathbf{1 7}, 82.7 \%$ for 23; (i) $\mathrm{CCl}_{3} \mathrm{CN}$, DBU, $\mathrm{CH}_{2} \mathrm{Cl}_{2}, 2 \mathrm{~h}, 88.7 \%$ for $10,94.3 \%$ for $\mathbf{1 8}, 90.3 \%$ for $\mathbf{2 4}$; (j) $\mathrm{CH}_{3} \mathrm{OH}-2-6 \% \mathrm{CH}_{3} \mathrm{COCl}, \mathrm{rt}, 12 \mathrm{~h}, 78.5 \%$ for $\mathbf{1 3}, 76.8 \%$ for $\mathbf{2 9}$; (k) satd $\mathrm{NH}_{3}-\mathrm{CH}_{3} \mathrm{OH}$, rt, $96 \mathrm{~h}, 91.0 \%$ for $\mathbf{2 0}, 92.5 \%$ for 31 .

\section{Experimental}

\subsection{General methods}

Optical rotations were determined at $25^{\circ} \mathrm{C}$ with a Perkin-Elmer Model 241-Mc automatic polarimeter. ${ }^{1} \mathrm{H}$ NMR and ${ }^{13} \mathrm{C}$ NMR spectra were recorded with
Bruker ARX 400 spectrometers $\left(400 \mathrm{MHz}\right.$ for ${ }^{1} \mathrm{H}$, $100 \mathrm{MHz}$ for ${ }^{13} \mathrm{C}$ ) for solutions in $\mathrm{CDCl}_{3}$ or $\mathrm{D}_{2} \mathrm{O}$ as indicated. Chemical shifts are given in ppm downfield from internal $\mathrm{Me}_{4} \mathrm{Si}$. Mass spectra were measured using MALDITOF-MS with CCA as matrix or recorded with a VG PLATFORM mass spectrometer using the ESI mode. Thin-layer chromatography (TLC) was 

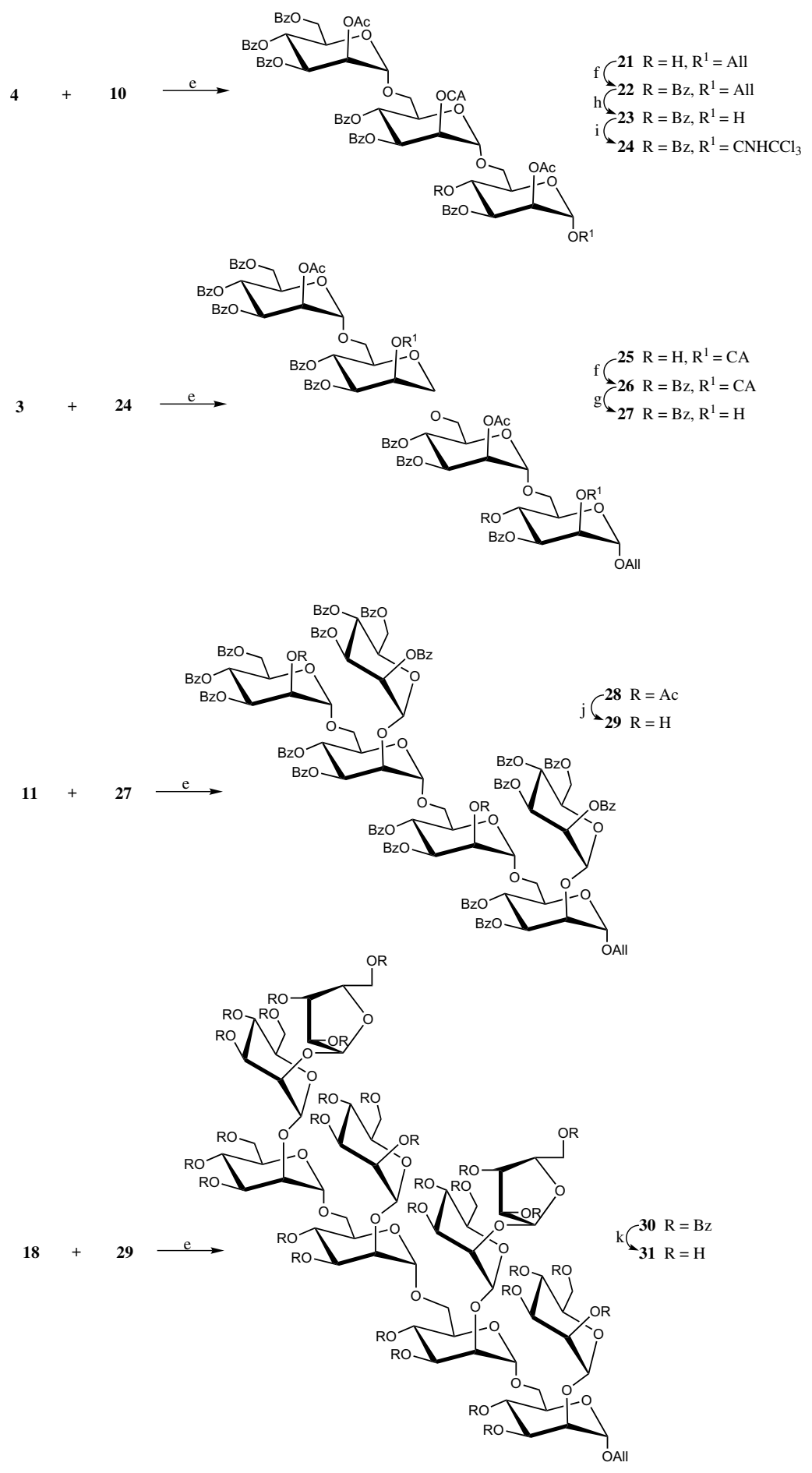

Scheme 2. Reagents and conditions: (a) $\mathrm{BzCl}, \mathrm{CH}_{2} \mathrm{Cl}_{2}$, pyridine, $90.7 \%$; (b), (c) $\mathrm{CH}_{2} \mathrm{ClCOCl}, \mathrm{CH}_{2} \mathrm{Cl}_{2}$, pyridine; $90 \%$ TFA, rt, $2 \mathrm{~h}$; $78.5 \%$ for two steps; (d), (c) $\mathrm{Ac}_{2} \mathrm{O}$-pyridine; $90 \%$ TFA, rt, $2 \mathrm{~h} ; 82.3 \%$ for two steps; (e) TMSOTf (0.01-0.05 equiv), $\mathrm{CH}_{2} \mathrm{Cl}_{2},-20$ to $0{ }^{\circ} \mathrm{C}, 2-4 \mathrm{~h}, 86.4 \%$ for $6,87.8 \%$ for $\mathbf{1 2}, 87.2 \%$ for $\mathbf{1 6}, 81.5 \%$ for $\mathbf{1 9}, 84.5 \%$ for $\mathbf{2 1}, 80.1 \%$ for $\mathbf{2 5}, 85.9 \%$ for $\mathbf{2 8}$, and $66.7 \%$ for $\mathbf{3 0}$, respectively; (f) BzCl-pyridine, $91.6 \%$ for $\mathbf{7}, 89.2 \%$ for 22, $85.5 \%$ for 26; (g) $\left(\mathrm{NH}_{2}\right)_{2} \mathrm{CS}, \mathrm{CH}_{2} \mathrm{Cl}_{2}-\mathrm{CH}_{3} \mathrm{OH}$, reflux, $16 \mathrm{~h}, 85.6 \%$ for $\mathbf{8}, 82.3 \%$ for 27; (h) $\mathrm{PdCl}_{2}, \mathrm{CH}_{3} \mathrm{OH}, \mathrm{rt}, 4 \mathrm{~h}, 84.5 \%$ for $\mathbf{9}, 82.4 \%$ for $\mathbf{1 7}, 82.7 \%$ for 23; (i) $\mathrm{CCl}_{3} \mathrm{CN}, \mathrm{DBU}, \mathrm{CH}_{2} \mathrm{Cl}_{2}, 2 \mathrm{~h}, 88.7 \%$ for $\mathbf{1 0}, 94.3 \%$ for $\mathbf{1 8}, 90.3 \%$ for $\mathbf{2 4}$; (j) $\mathrm{CH}_{3} \mathrm{OH}-2-6 \% \mathrm{CH}_{3} \mathrm{COCl}, \mathrm{rt}, 12 \mathrm{~h}, 78.5 \%$ for $\mathbf{1 3}, 76.8 \%$ for $\mathbf{2 9}$; (k) satd $\mathrm{NH}_{3}-\mathrm{CH}_{3} \mathrm{OH}$, rt, $96 \mathrm{~h}, 91.0 \%$ for $\mathbf{2 0}, 92.5 \%$ for $\mathbf{3 1}$.

performed on silica gel $\mathrm{HF}_{254}$ with detection by charring with $30 \%(\mathrm{v} / \mathrm{v}) \mathrm{H}_{2} \mathrm{SO}_{4}$ in $\mathrm{MeOH}$ or in some cases by a UV detector. Column chromatography was conducted by elution of a column $(16 \times 240 \mathrm{~mm}$, 
$18 \times 300 \mathrm{~mm}, 35 \times 400 \mathrm{~mm})$ of silica gel (100-200 mesh) with EtOAc-petroleum ether $\left(60-90^{\circ} \mathrm{C}\right)$ as the eluent. Solutions were concentrated at $<60^{\circ} \mathrm{C}$ under reduced pressure.

\subsection{General procedure for the glycosylations}

A mixture of the donor and acceptor was dried together under high vacuum for $2 \mathrm{~h}$, then dissolved in anhyd $\mathrm{CH}_{2} \mathrm{Cl}_{2}$ (1 mmol donor in $\left.20 \mathrm{~mL}\right)$. TMSOTf ( 0.05 equiv) was added dropwise at $-20^{\circ} \mathrm{C}$ with nitrogen protection. The reaction mixture was stirred for $3 \mathrm{~h}$, during which time the temperature was gradually raised to ambient temperature. Then the mixture was neutralized with $\mathrm{Et}_{3} \mathrm{~N}$. Concentration of the reaction mixture, followed by purification on a silica gel column, gave the desired products.

\subsection{Allyl 3- $O$-benzoyl-4,6-di- $O$-benzylidene- $\alpha$-D-manno- pyranoside (2)}

Compound $1(1.54 \mathrm{~g}, 5.0 \mathrm{mmol})$ was dissolved in dry $\mathrm{CH}_{2} \mathrm{Cl}_{2}(20 \mathrm{~mL})$ containing pyridine $(4 \mathrm{~mL})$, then under $\mathrm{N}_{2}$ protection, benzoyl chloride $(0.6 \mathrm{~mL}, 5.1 \mathrm{mmol})$ in anhyd $\mathrm{CH}_{2} \mathrm{Cl}_{2}(5 \mathrm{~mL})$ was added dropwise to the solution within $30 \mathrm{~min}$ at $0^{\circ} \mathrm{C}$. The reaction mixture was slowly raised to room temperature (rt) and stirred for $2 \mathrm{~h}$, at the end of which time TLC (3:1 petroleum etherEtOAc) indicated that the reaction was complete. The reaction mixture was diluted with $\mathrm{CH}_{2} \mathrm{Cl}_{2}(50 \mathrm{~mL})$, washed with water, $1 \mathrm{~N} \mathrm{HCl}$, and dried over $\mathrm{Na}_{2} \mathrm{SO}_{4}$. The solution was concentrated, and purification of the residue by column chromatography on a silica gel column (4:1 petroleum ether-EtOAc) gave compound 2 $(1.87 \mathrm{~g}, 90.7 \%)$ as a syrup: $[\alpha]_{\mathrm{D}}-8.6\left(c 1.0, \mathrm{CHCl}_{3}\right) ;{ }^{1} \mathrm{H}$ NMR $\left(400 \mathrm{MHz}, \mathrm{CDCl}_{3}\right): \delta 8.05-7.28(\mathrm{~m}, 10 \mathrm{H}, 2 P h)$, 5.95-5.86 $\left(\mathrm{m}, 1 \mathrm{H},-\mathrm{CH}_{2}-\mathrm{CH}=\mathrm{CH}_{2}\right), 5.57 \quad(\mathrm{~s}, 1 \mathrm{H}$, $\mathrm{PhCH}$ ), 5.56 (dd, $\left.1 \mathrm{H}, J_{2,3}=3.2 \mathrm{~Hz}, J_{3,4}=10.3 \mathrm{~Hz}, \mathrm{H}-3\right)$, 5.34-5.20 (m, $\left.2 \mathrm{H},-\mathrm{CH}_{2}-\mathrm{CH}=\mathrm{CH}_{2}\right), 4.89(\mathrm{~d}, 1 \mathrm{H}$, $\left.J_{1,2}=1.2 \mathrm{~Hz}, \mathrm{H}-1\right), 4.30-3.87$ (m, 7H, H-2, H-4, H-5, H$6,-\mathrm{CH}_{2}-\mathrm{CH}=\mathrm{CH}_{2}$ ). Anal. Calcd for $\mathrm{C}_{23} \mathrm{H}_{24} \mathrm{O}_{7}$ : C 66.98; H 5.87. Found: C 67.21; H 5.92.

\subsection{Allyl 3-O-benzoyl-2- $O$-chloroacetyl- $\alpha$-D-mannopyr- anoside (3)}

Compound $2(1.24 \mathrm{~g}, 3.0 \mathrm{mmol})$ was dissolved in dry $\mathrm{CH}_{2} \mathrm{Cl}_{2}(20 \mathrm{~mL})$ containing pyridine $(3 \mathrm{~mL})$, then under $\mathrm{N}_{2}$ protection, chloroacetyl chloride $(0.27 \mathrm{~mL}$, $3.3 \mathrm{mmol})$ in anhyd $\mathrm{CH}_{2} \mathrm{Cl}_{2}(5 \mathrm{~mL})$ was added dropwise to the solution. The reaction mixture was stirred for $2 \mathrm{~h}$, then was diluted with $\mathrm{CH}_{2} \mathrm{Cl}_{2}(40 \mathrm{~mL})$, washed with water, $1 \mathrm{~N} \mathrm{HCl}$, and dried over $\mathrm{Na}_{2} \mathrm{SO}_{4}$. The solution was concentrated, the residue was dissolved in $90 \%$ TFA $(20 \mathrm{~mL})$, and the mixture was stirred for $2 \mathrm{~h}$ at $\mathrm{rt}$, at the end of which time TLC (2:1 petroleum ether-EtOAc) indicated that the reaction was complete. The mixture was diluted with toluene $(80 \mathrm{~mL})$ and concentrated in vacuo directly. The residue was passed through a short silica gel column with 1:1 petroleum ether-EtOAc as the eluent to give $3(0.94 \mathrm{~g}, 78.5 \%$ for two steps) as syrup: $[\alpha]_{\mathrm{D}}+96.7\left(c 1.0, \mathrm{CHCl}_{3}\right) ;{ }^{1} \mathrm{H} \mathrm{NMR}\left(400 \mathrm{MHz}, \mathrm{CDCl}_{3}\right)$ : $\delta$ 8.00-7.43 (m, 5H, Ph), 5.96-5.86 (m, $1 \mathrm{H},-\mathrm{CH}_{2}-$ $\left.\mathrm{C} H=\mathrm{CH}_{2}\right), 5.52\left(\mathrm{dd}, 1 \mathrm{H}, J_{2,3}=3.3 \mathrm{~Hz}, J_{3,4}=9.9 \mathrm{~Hz}, \mathrm{H}-\right.$ 3), $5.44\left(\mathrm{dd}, 1 \mathrm{H}, J_{1,2}=1.6 \mathrm{~Hz}, J_{2,3}=3.3 \mathrm{~Hz}, \mathrm{H}-2\right), 5.36-$ $5.24\left(\mathrm{~m}, 2 \mathrm{H},-\mathrm{CH}_{2}-\mathrm{CH}=\mathrm{CH}_{2}\right), 4.93\left(\mathrm{~d}, 1 \mathrm{H}, J_{1,2}=\right.$ $1.6 \mathrm{~Hz}, \mathrm{H}-1), 4.26-4.02\left(\mathrm{~m}, 5 \mathrm{H}, \mathrm{H}-4, \mathrm{CH}_{2} \mathrm{ClCO},-\mathrm{CH}_{2}-\right.$ $\left.\mathrm{CH}=\mathrm{CH}_{2}\right), 3.93-3.82(\mathrm{~m}, 3 \mathrm{H}, \mathrm{H}-5, \mathrm{H}-6)$. Anal. Calcd for $\mathrm{C}_{18} \mathrm{H}_{21} \mathrm{ClO}_{8}$ : C 53.94; $\mathrm{H}$ 5.28. Found: C 54.09; H 5.33 .

\subsection{Allyl 2- $O$-acetyl-3- $O$-benzoyl- $\alpha$-D-mannopyranoside}

(4)

To a solution of $\mathbf{1 6}(412 \mathrm{mg}, 1 \mathrm{mmol})$ in pyridine $(10 \mathrm{~mL})$ was added $\mathrm{Ac}_{2} \mathrm{O}(5 \mathrm{~mL}, 5 \mathrm{mmol})$. The reaction mixture, was stirred at $\mathrm{rt}$ for $12 \mathrm{~h}$, at the end of which time TLC (3:1 petroleum ether-EtOAc) indicated that the reaction was complete. The reaction mixture was concentrated, the residue was dissolved in $90 \%$ TFA $(10 \mathrm{~mL})$, and the mixture was stirred for $2 \mathrm{~h}$ at $\mathrm{rt}$, at the end of which time TLC (2:1 petroleum ether-EtOAc) indicated that the reaction was complete. The mixture was diluted with toluene $(40 \mathrm{~mL})$ and concentrated in vacuo directly. The residue was passed through a short silica gel column with 1:1 petroleum ether-EtOAc as the eluent to give $\mathbf{4}$ (302 mg, $82.3 \%$ for two steps) as syrup: $[\alpha]_{\mathrm{D}}+62.6(c 1.0$, $\left.\mathrm{CHCl}_{3}\right) ;{ }^{1} \mathrm{H}$ NMR $\left(400 \mathrm{MHz}, \mathrm{CDCl}_{3}\right): \delta \quad 8.00-7.43$ $(\mathrm{m}, 5 \mathrm{H}, \mathrm{Ph}), 5.96-5.86\left(\mathrm{~m}, 1 \mathrm{H},-\mathrm{CH}_{2}-\mathrm{CH}=\mathrm{CH}_{2}\right), 5.48$ $\left(\mathrm{dd}, 1 \mathrm{H}, J_{2,3}=3.5 \mathrm{~Hz}, J_{3,4}=9.9 \mathrm{~Hz}, \mathrm{H}-3\right), 5.39(\mathrm{dd}, 1 \mathrm{H}$, $\left.J_{1,2}=1.6 \mathrm{~Hz}, J_{2,3}=3.5 \mathrm{~Hz}, \mathrm{H}-2\right), 5.35-5.23(\mathrm{~m}, 2 \mathrm{H}$, $\left.-\mathrm{CH}_{2}-\mathrm{CH}=\mathrm{CH}_{2}\right), 4.90\left(\mathrm{~d}, 1 \mathrm{H}, J_{1,2}=1.6 \mathrm{~Hz}, \mathrm{H}-1\right), 4.25$ $4.01 \quad\left(\mathrm{~m}, \quad 3 \mathrm{H}, \quad \mathrm{H}-4, \quad-\mathrm{CH}_{2}-\mathrm{CH}=\mathrm{CH}_{2}\right), \quad 3.94-3.82$ (m, 3H, H-5, H-6), 2.15 (s, 3H, $\left.\mathrm{CH}_{3} \mathrm{CO}\right)$. Anal. Calcd for $\mathrm{C}_{18} \mathrm{H}_{22} \mathrm{O}_{8}$ : C 59.01; H 6.05. Found: C 59.28; $\mathrm{H}$ 6.11 .

\subsection{Allyl 2- $O$-acetyl-3,4,6-tri- $O$-benzoyl- $\alpha$-D-mannopyr- anosyl-( $1 \rightarrow 6)$-3- $O$-benzoyl-2- $O$-chloroacetyl- $\alpha$-D-manno- pyranoside (6)}

Donor 5 (996 mg, $1.47 \mathrm{mmol}$ ) was coupled with acceptor $3(490 \mathrm{mg}, 1.22 \mathrm{mmol})$ as described in the general procedure, and the product was purified by chromatography with 3:1 petroleum ether-EtOAc as the eluent to give $10(969 \mathrm{mg}, 86.4 \%)$ as a foamy solid: $[\alpha]_{\mathrm{D}}+49.6(\mathrm{c}$ 1.0, $\left.\mathrm{CHCl}_{3}\right) ;{ }^{1} \mathrm{H}$ NMR $\left(400 \mathrm{MHz}, \mathrm{CDCl}_{3}\right): \delta 8.07-7.26$ $(\mathrm{m}, 20 \mathrm{H}, \quad 4 P h), \quad 5.98-5.88\left(\mathrm{~m}, 2 \mathrm{H}, \quad \mathrm{H}-4^{\prime},-\mathrm{CH}_{2}\right.$ $\left.\mathrm{CH}=\mathrm{CH}_{2}\right), 5.84\left(\mathrm{dd}, 1 \mathrm{H}, J_{2^{\prime}, 3^{\prime}}=3.3 \mathrm{~Hz}, J_{3^{\prime}, 4^{\prime}}=10.1 \mathrm{~Hz}\right.$, $\left.\mathrm{H}-3^{\prime}\right), 5.60\left(\mathrm{dd}, 1 \mathrm{H}, J_{1^{\prime}, 2^{\prime}}=1.8 \mathrm{~Hz}, J_{2^{\prime}, 3^{\prime}}=3.3 \mathrm{~Hz}, \mathrm{H}-2^{\prime}\right)$, 
$5.55(\mathrm{dd}, 1 \mathrm{H}) 5.38-5.24\left(\mathrm{~m}, 2 \mathrm{H},-\mathrm{CH}_{2}-\mathrm{CH}=\mathrm{CH}_{2}\right), 5.15$ $\left(\mathrm{d}, 1 \mathrm{H}, J_{1^{\prime}, 2^{\prime}}=1.8 \mathrm{~Hz}, \mathrm{H}-1^{\prime}\right), 4.95\left(\mathrm{~d}, 1 \mathrm{H}, J_{1,2}=1.8 \mathrm{~Hz}\right.$, $\mathrm{H}-1), 4.66-4.61$ (m, $\left.1 \mathrm{H}, \mathrm{H}-5^{\prime}\right), 4.54-4.48$ (m, 2H, H-5, H-6'a), $4.36\left(\mathrm{dd}, 1 \mathrm{H}, J_{3,4}=J_{4,5}=9.8 \mathrm{~Hz}, \mathrm{H}-4\right), 4.25$ (ABq, $\left.2 \mathrm{H}, J=20.4 \mathrm{~Hz}, \mathrm{C} H_{2} \mathrm{ClCO}\right), 4.24-3.90(\mathrm{~m}, 5 \mathrm{H}$, H-6a, H-6b, H-6'b, $-\mathrm{CH}_{2}-\mathrm{CH}=\mathrm{CH}_{2}$ ), 2.11 (s, 3H, $\mathrm{CH}_{3} \mathrm{CO}$ ). Anal. Calcd for $\mathrm{C}_{47} \mathrm{H}_{45} \mathrm{ClO}_{17}$ : C 61.54; $\mathrm{H} 4.94$. Found: C 61.38; H 5.01.

\subsection{Allyl 2- $O$-acetyl-3,4,6-tri- $O$-benzoyl- $\alpha$-D-mannopyr- anosyl-( $1 \rightarrow 6)-3,4-d i-O$-benzoyl-2- $O$-chloroacetyl- $\alpha-\mathrm{D}-$ mannopyranoside (7)}

To a solution of $6(842 \mathrm{mg}, 0.92 \mathrm{mmol})$ in pyridine $(10 \mathrm{~mL})$ was added benzoyl chloride $(0.13 \mathrm{~mL}$, $1.1 \mathrm{mmol})$. After stirring the mixture overnight at $\mathrm{rt}$, TLC (2:1 petroleum ether-EtOAc) indicated that the reaction was complete. $\mathrm{MeOH}$ (one drop) was added to the reaction mixture, and stirring was continued for $10 \mathrm{~min}$. Water $(10 \mathrm{~mL})$ was added, and the mixture was extracted with $\mathrm{CH}_{2} \mathrm{Cl}_{2}(3 \times 10 \mathrm{~mL})$. The extract was washed with $\mathrm{M} \mathrm{HCl}$ and satd aq $\mathrm{NaHCO}_{3}$, dried $\left(\mathrm{Na}_{2}\right.$ $\mathrm{SO}_{4}$ ), and concentrated. Purification by flash chromatography (3:1 petroleum ether-EtOAc) gave $7(859 \mathrm{mg}$, 91.6\%) as a foamy solid: $[\alpha]_{\mathrm{D}}+40.56\left(c 1.0, \mathrm{CHCl}_{3}\right) ;{ }^{1} \mathrm{H}$ NMR $\left(400 \mathrm{MHz}, \mathrm{CDCl}_{3}\right)$ : 8.04-7.26 (m, 25H, 5Ph), 6.05-5.95 (m, $\left.1 \mathrm{H},-\mathrm{CH}_{2}-\mathrm{CH}=\mathrm{CH}_{2}\right), 5.97(\mathrm{dd}, 1 \mathrm{H}$, $\left.J_{3^{\prime}, 4^{\prime}}=J_{4^{\prime}, 5^{\prime}}=10.1 \mathrm{~Hz}, \quad \mathrm{H}-4^{\prime}\right), \quad 5.93\left(\mathrm{dd}, \quad 1 \mathrm{H}, \quad J_{3,4}=\right.$ $\left.J_{4,5}=10.1 \mathrm{~Hz}, \quad \mathrm{H}-4\right), 5.88\left(\mathrm{dd}, 1 \mathrm{H}, \quad J_{2^{\prime}, 3^{\prime}}=3.3 \mathrm{~Hz}\right.$, $\left.J_{3^{\prime}, 4^{\prime}}=10.1 \mathrm{~Hz}, \quad \mathrm{H}-3^{\prime}\right), \quad 5.85\left(\mathrm{dd}, \quad 1 \mathrm{H}, \quad J_{2,3}=3.3 \mathrm{~Hz}\right.$, $\left.J_{3,4}=10.1 \mathrm{~Hz}, \quad \mathrm{H}-3\right), \quad 5.58\left(\mathrm{dd}, 1 \mathrm{H}, J_{1^{\prime}, 2^{\prime}}=1.8 \mathrm{~Hz}\right.$, $\left.J_{2^{\prime}, 3^{\prime}}=3.3 \mathrm{~Hz}, \quad \mathrm{H}-2^{\prime}\right), \quad 5.55 \quad\left(\mathrm{dd}, \quad 1 \mathrm{H}, \quad J_{1,2}=1.8 \mathrm{~Hz}\right.$, $\left.J_{2,3}=3.3 \mathrm{~Hz}, \mathrm{H}-2\right), 5.47-5.31\left(\mathrm{~m}, 2 \mathrm{H},-\mathrm{CH}_{2}-\mathrm{CH}=\mathrm{CH}_{2}\right)$, $5.04\left(\mathrm{~d}, \quad 1 \mathrm{H}, \quad J_{1^{\prime}, 2^{\prime}}=1.8 \mathrm{~Hz}, \mathrm{H}-1^{\prime}\right), 5.03(\mathrm{~d}, \quad 1 \mathrm{H}$, $\left.J_{1,2}=1.8 \mathrm{~Hz}, \quad \mathrm{H}-1\right), 4.47\left(\mathrm{dd}, \quad 1 \mathrm{H}, \quad J_{5^{\prime}, 6^{\prime} \mathrm{a}}=2.4 \mathrm{~Hz}\right.$, $\left.J_{6^{\prime} \mathrm{a}, 6^{\prime} \mathrm{b}}=11.6 \mathrm{~Hz}, \mathrm{H}-6^{\prime} \mathrm{a}\right), 4.43-3.72\left(\mathrm{~m}, 9 \mathrm{H}, \mathrm{H}-5, \mathrm{H}-5^{\prime}\right.$, H-6a, H-6b, H-6'b, $\left.\mathrm{CH}_{2} \mathrm{ClCO},-\mathrm{CH}_{2}-\mathrm{CH}=\mathrm{CH}_{2}\right), 2.11$ (s, $3 \mathrm{H}, \mathrm{CH}_{3} \mathrm{CO}$ ). Anal. Calcd for $\mathrm{C}_{54} \mathrm{H}_{49} \mathrm{ClO}_{18}$ : C 63.50; H 4.84. Found: C 63.75; H 4.78.

\subsection{Allyl 2- $O$-acetyl-3,4,6-tri- $O$-benzoyl- $\alpha$-D-mannopyr- anosyl-( $1 \rightarrow 6)-3,4-d i-O$-benzoyl- $\alpha$-D-mannopyranoside} (8)

To a solution of $7(320 \mathrm{mg}, 0.31 \mathrm{mmol})$ in $\mathrm{MeOH}$ $(10 \mathrm{~mL})-\mathrm{CH}_{2} \mathrm{Cl}_{2}(15 \mathrm{~mL})$ was added thiourea $(600 \mathrm{mg})$, and the mixture was refluxed for $16 \mathrm{~h}$, at the end of which time TLC (2:1 petroleum ether-EtOAc) indicated that the reaction was complete. The mixture was concentrated. The residue was passed through a silica-gel column with 3:1 petroleum ether-EtOAc as the eluent to give 8 (253 $\mathrm{mg}, 85.6 \%$ for two steps) as a foamy solid: $[\alpha]_{\mathrm{D}}+32.2\left(c 1.0, \mathrm{CHCl}_{3}\right) ;{ }^{1} \mathrm{H}$ NMR $\left(400 \mathrm{MHz}, \mathrm{CDCl}_{3}\right)$ : $\delta 8.01-7.26(\mathrm{~m}, 25 \mathrm{H}, 5 \mathrm{Ph}), 6.08-5.98\left(\mathrm{~m}, 1 \mathrm{H},-\mathrm{CH}_{2}-\right.$ $\left.\mathrm{C} H=\mathrm{CH}_{2}\right), 5.88\left(\mathrm{dd}, 1 \mathrm{H}, J_{3^{\prime}, 4^{\prime}}=J_{4^{\prime}, 5^{\prime}}=10.1 \mathrm{~Hz}, \mathrm{H}-4^{\prime}\right)$, $5.87\left(\mathrm{dd}, 1 \mathrm{H}, J_{3,4}=J_{4,5}=10.1 \mathrm{~Hz}, \mathrm{H}-4\right), 5.85(\mathrm{dd}, 1 \mathrm{H}$, $\left.J_{2^{\prime}, 3^{\prime}}=3.2 \mathrm{~Hz}, \quad J_{3^{\prime}, 4^{\prime}}=10.1 \mathrm{~Hz}, \quad \mathrm{H}-3^{\prime}\right), 5.70(\mathrm{dd}, 1 \mathrm{H}$, $\left.J_{2,3}=3.1 \mathrm{~Hz}, \quad J_{3,4}=10.1 \mathrm{~Hz}, \quad \mathrm{H}-3\right), 5.51 \quad(\mathrm{dd}, \quad 1 \mathrm{H}$, $\left.J_{1^{\prime}, 2^{\prime}}=1.5 \mathrm{~Hz}, J_{2^{\prime}, 3^{\prime}}=3.2 \mathrm{~Hz}, \mathrm{H}-2^{\prime}\right), 5.47-5.29(\mathrm{~m}, 2 \mathrm{H}$, $\left.-\mathrm{CH}_{2}-\mathrm{CH}=\mathrm{CH}_{2}\right), 5.04\left(\mathrm{~d}, 1 \mathrm{H}, J_{1^{\prime}, 2^{\prime}}=1.5 \mathrm{~Hz}, \mathrm{H}-1^{\prime}\right)$, $5.03\left(\mathrm{~d}, 1 \mathrm{H}, J_{1,2}=1.6 \mathrm{~Hz}, \mathrm{H}-1\right), 4.50-3.71(\mathrm{~m}, 9 \mathrm{H}, \mathrm{H}-2$, $\left.\mathrm{H}-5, \mathrm{H}-5^{\prime}, \mathrm{H}-6, \mathrm{H}-6^{\prime},-\mathrm{CH}_{2}-\mathrm{CH}=\mathrm{CH}_{2}\right), 2.12(\mathrm{~s}, 3 \mathrm{H}$, $\mathrm{CH}_{3} \mathrm{CO}$ ). Anal. Calcd for $\mathrm{C}_{52} \mathrm{H}_{48} \mathrm{O}_{17}: \mathrm{C} 66.10 ; \mathrm{H} 5.12$. Found: C 65.87; H 5.09.

3.9. 2-O-Acetyl-3,4,6-tri- $O$-benzoyl- $\alpha$-D-mannopyranosyl-(1 $\rightarrow 6)$-3,4-di- $O$-benzoyl-2- $O$-chloroacetyl- $\alpha$-Dmannopyranosyl trichloroacetimidate (10)

To a solution of $7(515 \mathrm{mg}, 0.50 \mathrm{mmol})$ in anhyd $\mathrm{MeOH}$ $(10 \mathrm{~mL})$ was added $\mathrm{PdCl}_{2}(30 \mathrm{mg})$. After stirring the mixture at $\mathrm{rt}$ for $2 \mathrm{~h}$, TLC (2:1 petroleum ether-EtOAc) indicated that the reaction was complete. The mixture was filtered, the solution was concentrated to dryness, and the resultant residue was purified by flash chromatography (2.5:1 petroleum ether-EtOAc) to give 9 $(418 \mathrm{mg}, 84.5 \%)$ as a white foam. A mixture of 9 $(418 \mathrm{mg}, \quad 0.43 \mathrm{mmol}), \quad$ trichloroacetonitrile $(80 \mu \mathrm{L}$, $0.80 \mathrm{mmol}$ ) and 1,8-diazabicyclo[5.4.0]-undecene (DBU) $(25 \mu \mathrm{L})$ in dry $\mathrm{CH}_{2} \mathrm{Cl}_{2}(10 \mathrm{~mL})$ was stirred under nitrogen for $3 \mathrm{~h}$ and then concentrated. The residue was purified by flash chromatography (3:1 petroleum etherEtOAc) to give $\mathbf{1 0}(425 \mathrm{mg}, 88.7 \%)$ as a foamy solid: $[\alpha]_{\mathrm{D}}$ +55.5 (c 1.0, $\left.\mathrm{CHCl}_{3}\right) ;{ }^{1} \mathrm{H}$ NMR $\left(400 \mathrm{MHz}, \mathrm{CDCl}_{3}\right): \delta$ $\left.8.97(\mathrm{~s}, 1 \mathrm{H}, \mathrm{CNHCCl})_{3}\right), 8.08-7.26(\mathrm{~m}, 25 \mathrm{H}, 5 \mathrm{Ph}), 6.44$ $\left(\mathrm{d}, \quad 1 \mathrm{H}, \quad J_{1,2}=1.5 \mathrm{~Hz}, \mathrm{H}-1\right), 6.12\left(\mathrm{dd}, 1 \mathrm{H}, J_{3^{\prime}, 4^{\prime}}=\right.$ $\left.J_{4^{\prime}, 5^{\prime}}=10.0 \mathrm{~Hz}, \mathrm{H}-4^{\prime}\right), 5.93\left(\mathrm{dd}, 1 \mathrm{H}, J_{3,4}=J_{4,5}=9.9 \mathrm{~Hz}\right.$, H-4), 5.91-5.82 (m, 2H, H-3, H-3'), $5.78(\mathrm{dd}, 1 \mathrm{H}$, $\left.J_{1^{\prime}, 2^{\prime}}=1.4 \mathrm{~Hz}, \quad J_{2^{\prime}, 3^{\prime}}=3.2 \mathrm{~Hz}, \quad \mathrm{H}-2^{\prime}\right), 5.57(\mathrm{dd}, \quad 1 \mathrm{H}$, $\left.J_{1,2}=1.5 \mathrm{~Hz}, \quad J_{2,3}=3.0 \mathrm{~Hz}, \quad \mathrm{H}-2\right), \quad 5.01 \quad(\mathrm{~d}, \quad 1 \mathrm{H}$, $\left.J_{1^{\prime}, 2^{\prime}}=1.4 \mathrm{~Hz}, \mathrm{H}-1^{\prime}\right), 4.52-3.78\left(\mathrm{~m}, 8 \mathrm{H}, \mathrm{H}-5, \mathrm{H}-5^{\prime}, \mathrm{H}-6\right.$, $\mathrm{H}-6^{\prime}, \mathrm{CH}_{2} \mathrm{ClCO}$ ), 2.12 (s, $3 \mathrm{H}, \mathrm{CH}_{3} \mathrm{CO}$ ). Anal. Calcd for $\mathrm{C}_{53} \mathrm{H}_{45} \mathrm{Cl}_{4} \mathrm{NO}_{18}$ : C 56.55; $\mathrm{H} 4.03$. Found: C 56.32; $\mathrm{H}$ 3.97 .

3.10. Allyl 2- $O$-acetyl-3,4,6-tri- $O$-benzoyl- $\alpha$-D-mannopyranosyl-( $1 \rightarrow 6)$-[2,3,4,6-tetra- $O$-benzoyl- $\alpha$-D-mannopyranosyl-( $1 \rightarrow 2)$-3,4-di- $O$-benzoyl- $\alpha$-D-mannopyranoside (12)

Compound $\mathbf{8}(240 \mathrm{mg}, 0.25 \mathrm{mmol})$ and $\mathbf{1 1}(226 \mathrm{mg}$, $0.31 \mathrm{mmol}$ ) were coupled under the same conditions as those used for preparation of $\mathbf{6}$ from $\mathbf{3}$ and $\mathbf{5}$, giving $\mathbf{1 2}$ $(340 \mathrm{mg}, 87.8 \%)$ as a foamy solid: $[\alpha]_{\mathrm{D}}-32.5(c 1.0$, $\left.\mathrm{CHCl}_{3}\right) ;{ }^{1} \mathrm{H}$ NMR $\left(400 \mathrm{MHz}, \mathrm{CDCl}_{3}\right): \delta 8.13-7.05(\mathrm{~m}$, $45 \mathrm{H}, 9 P h), 6.17\left(\mathrm{dd}, 1 \mathrm{H}, J_{3,4}=J_{4,5}=9.8 \mathrm{~Hz}, \mathrm{H}-4\right), 6.10$ $5.91\left(\mathrm{~m}, 7 \mathrm{H}, \mathrm{H}-2,3 \mathrm{H}-3,2 \mathrm{H}-4,-\mathrm{CH}_{2}-\mathrm{CH}=\mathrm{CH}_{2}\right), 5.63$ $\left(\mathrm{dd}, 1 \mathrm{H}, J_{1,2}=1.4 \mathrm{~Hz}, J_{2,3}=2.9 \mathrm{~Hz}, \mathrm{H}-2\right), 5.50-5.29(\mathrm{~m}$, $\left.2 \mathrm{H},-\mathrm{CH}_{2}-\mathrm{C}=\mathrm{HCH}_{2}\right), 5.32\left(\mathrm{~d}, 1 \mathrm{H}, J_{1,2}=1.2 \mathrm{~Hz}, \mathrm{H}-1\right)$, $5.27\left(\mathrm{~d}, \quad 1 \mathrm{H}, \quad J_{1,2}=1.3 \mathrm{~Hz}, \quad \mathrm{H}-1\right), 5.27(\mathrm{~d}, \quad 1 \mathrm{H}$, 
$\left.J_{1,2}=1.4 \mathrm{~Hz}, \mathrm{H}-1\right), 5.08\left(\mathrm{~d}, 1 \mathrm{H}, J_{1,2}=1.5 \mathrm{~Hz}, \mathrm{H}-1\right)$, 4.77-3.79 (m, 12H, H-2, 3H-5, 6H-6, $-\mathrm{CH}_{2}-\mathrm{CH}=\mathrm{CH}_{2}$ ), 2.06 (s, 3H, $\left.\mathrm{CH}_{3} \mathrm{CO}\right) ;{ }^{13} \mathrm{C} \mathrm{NMR}\left(100 \mathrm{MHz}, \mathrm{CDCl}_{3}\right): \delta$ 169.67 $\left(\mathrm{CH}_{3} \mathrm{CO}\right), 166.09,165.99,165.87,165.67,165.60$, 165.29, 164.95, 164.81, $167.80(\mathrm{PhCO}), 99.66,97.86$, 97.55 (C-1), 71.06, 70.23, 70.03, 69.97, 69.76, 69.74, $68.83,68.67,67.35,66.86,66.83,66.73,63.02,62.89$, 60.34, 20.69. Anal. Calcd for $\mathrm{C}_{86} \mathrm{H}_{74} \mathrm{O}_{26}: \mathrm{C} 67.80 ; \mathrm{H}$ 4.90. Found: C 67.68; H 4.83.

\subsection{Allyl 3,4,6-tri- $O$-benzoyl- $\alpha$-D-mannopyranosyl- $(1 \rightarrow 6)$-[2,3,4,6-tetra- $O$-benzoyl- $\alpha$-D-mannopyranosyl- $(1 \rightarrow 2)]-3,4-d i-O$-benzoyl- $\alpha$-D-mannopyranoside (13)}

To a solution of $12(325 \mathrm{mg}, 0.21 \mathrm{mmol})$ in anhyd $\mathrm{CH}_{2} \mathrm{Cl}_{2}(5 \mathrm{~mL})$ was added anhyd $\mathrm{MeOH}(25 \mathrm{~mL})$, then acetyl chloride $(1 \mathrm{~mL})$ was added to the reaction mixture at $0^{\circ} \mathrm{C}$. The solution was stoppered in a flask and stirred at $\mathrm{rt}$ until TLC (1:1 petroleum ether-EtOAc) showed that the reaction was complete. The solution was neutralized with $\mathrm{Et}_{3} \mathrm{~N}$, then concentrated to dryness. The residue was passed through a short silica gel column to give $13(248 \mathrm{mg}, 78.5 \%)$ as a foamy solid: $[\alpha]_{\mathrm{D}}-11.6(c$ 1.0, $\left.\mathrm{CHCl}_{3}\right) ;{ }^{1} \mathrm{H}$ NMR (400 MHz, $\left.\mathrm{CDCl}_{3}\right): \delta 8.02-7.04$ $(\mathrm{m}, 45 \mathrm{H}, 9 P h), 6.25\left(\mathrm{dd}, 1 \mathrm{H}, J_{3,4}=J_{4,5}=9.8 \mathrm{~Hz}, \mathrm{H}-4\right)$, 6.11-5.79 (m, 7H, H-2, 3H-3, 2H-4, $-\mathrm{CH}_{2}-\mathrm{CH}=\mathrm{CH}_{2}$ ), 5.54 (s, 1H, H-1), 5.40-5.27 (m, 2H, $\left.-\mathrm{CH}_{2}-\mathrm{CH}=\mathrm{CH}_{2}\right)$, 5.37 (s, 1H, H-1), 5.17 (s, 1H, H-1), 4.81 (m, 1H, H-2), 4.72-3.73 (m, 12H, H-2, 3H-5, 6H-6, $-\mathrm{CH}_{2}-\mathrm{CH}=\mathrm{CH}_{2}$ ); ${ }^{13} \mathrm{C} \mathrm{NMR}\left(100 \mathrm{MHz}, \mathrm{CDCl}_{3}\right): \delta 166.25,166.10,165.83$, $165.75,165.65,165.64,165.33,164.79,164.71$ (PhCO), 100.60, 99.41, 97.97 (C-1), 72.80, 71.34, 71.13, 70.35, $69.89,69.70,68.89,68.63,67.34,67.10,66.54,64.65$, 63.74, 63.01, 60.39. Anal. Calcd for $\mathrm{C}_{84} \mathrm{H}_{72} \mathrm{O}_{25}$ : C 68.10; H 4.90. Found: C 67.95; H 4.91.

\subsection{Allyl 2,3,5-tri- $O$-benzoyl- $\alpha$-D-arabinofuranosyl- $(1 \rightarrow 2)-3,4,6$-tri- $O$-benzoyl- $\alpha$-D-mannopyranoside (16)}

Acceptor 15 (266 mg, $0.50 \mathrm{mmol})$ was coupled with donor $14(364 \mathrm{mg}, 0.60 \mathrm{mmol})$ as described in the general procedure, and the product was purified by chromatography with $1.5: 1$ petroleum ether-EtOAc as the eluent to give $16(426 \mathrm{mg}, 87.2 \%)$ as a foamy solid: $[\alpha]_{\mathrm{D}}$ -36.6 (c 1.0, $\mathrm{CHCl}_{3}$ ); ${ }^{1} \mathrm{H}$ NMR $\left(400 \mathrm{MHz}, \mathrm{CDCl}_{3}\right): \delta$ 8.14-7.21 (m, 30H, 6Ph), 6.01 (dd, $1 \mathrm{H}$, $\left.J_{3,4}=J_{4,5}=10.0 \mathrm{~Hz}, \operatorname{Man} p \mathrm{H}-4\right), 6.10-5.90(\mathrm{~m}, 1 \mathrm{H}$, $\left.-\mathrm{CH}_{2}-\mathrm{CH}=\mathrm{CH}_{2}\right), \quad 5.87 \quad\left(\mathrm{dd}, \quad 1 \mathrm{H}, \quad J_{2,3}=3.2 \mathrm{~Hz}\right.$, $\left.J_{3,4}=10.0 \mathrm{~Hz}, \operatorname{Man} p \mathrm{H}-3\right), 5.71\left(\mathrm{~d}, 1 \mathrm{H}, J_{2,3}=1.1 \mathrm{~Hz}\right.$, Araf H-2), $5.62\left(\mathrm{dd}, 1 \mathrm{H}, J_{2,3}=1.1 \mathrm{~Hz}, J_{3,4}=3.5 \mathrm{~Hz}\right.$, Araf $\mathrm{H}-3), 5.48$ (s, 1H, Araf $\mathrm{H}-1), 5.33-5.18(\mathrm{~m}, 2 \mathrm{H}$, $\left.-\mathrm{CH}_{2}-\mathrm{CH}=\mathrm{CH}_{2}\right), 5.13\left(\mathrm{~d}, 1 \mathrm{H}, J_{1,2}=1.7 \mathrm{~Hz}, \operatorname{Man} p\right.$ $\mathrm{H}-1)$, 4.76-4.36 (m, 7H, Manp H-2, H-5, 2H-6, Ara $f$ H-4, 2H-5), 4.31-4.06 (m, 2H, $-\mathrm{CH}_{2}-\mathrm{CH}=\mathrm{CH}_{2}$ ). Anal. Calcd for $\mathrm{C}_{56} \mathrm{H}_{48} \mathrm{O}_{16}$ : C 68.85; $\mathrm{H}$ 4.95. Found: $\mathrm{C} 68.95$; H 5.02 .
3.13. 2,3,5-Tri- $O$-benzoyl- $\alpha$-D-arabinofuranosyl-( $1 \rightarrow 2)$ 3,4,6-tri- $O$-benzoyl- $\alpha$-D-mannopyranosyl trichloroacetimidate (18)

Deallylation of disaccharide $16(415 \mathrm{mg}, 0.07 \mathrm{mmol})$, followed by trichloroacetimidation under the same conditions as those used for preparation of $\mathbf{1 0}$ from $\mathbf{7}$ gave a residue that was purified by flash chromatography (3:1 petroleum ether-EtOAc) to give $\mathbf{1 8}(357 \mathrm{mg}$, $77.7 \%$ for two steps) as a foamy solid: $[\alpha]_{\mathrm{D}}-14.5(c 1.0$, $\left.\mathrm{CHCl}_{3}\right) ;{ }^{1} \mathrm{H}$ NMR $\left(400 \mathrm{MHz}, \mathrm{CDCl}_{3}\right): \delta 8.81(\mathrm{~s}, 1 \mathrm{H}$, $\left.\mathrm{CNHCCl}_{3}\right), 8.11-7.23(\mathrm{~m}, 30 \mathrm{H}, 6 P h), 6.56(\mathrm{~d}, 1 \mathrm{H}$, $J_{1,2}=1.6 \mathrm{~Hz}, \quad$ Man $\left.p \mathrm{H}-1\right), 6.15\left(\mathrm{dd}, \quad 1 \mathrm{H}, \quad J_{3,4}=\right.$ $\left.J_{4,5}=10.1 \mathrm{~Hz}, \operatorname{Man} p \mathrm{H}-4\right), 5.89\left(\mathrm{dd}, 1 \mathrm{H}, J_{2,3}=3.2 \mathrm{~Hz}\right.$, $\left.J_{3,4}=10.1 \mathrm{~Hz}, \operatorname{Man} p \mathrm{H}-3\right), 5.72\left(\mathrm{~d}, 1 \mathrm{H}, J_{2,3}=1.1 \mathrm{~Hz}\right.$, Araf $\mathrm{H}-2), 5.63\left(\mathrm{dd}, 1 \mathrm{H}, J_{2,3}=1.1 \mathrm{~Hz}, J_{3,4}=4.4 \mathrm{~Hz}\right.$, Araf $\mathrm{H}-3), 5.53$ (s, $1 \mathrm{H}$, Araf $\mathrm{H}-1), 4.81-4.37$ (m, 7H, Man $p$ H-2, H-5, 2 H-6, Araf H-4, 2H-5). Anal. Calcd for $\mathrm{C}_{55} \mathrm{H}_{44} \mathrm{Cl}_{3} \mathrm{NO}_{16}$ : C 61.09; $\mathrm{H}$ 4.10. Found: $\mathrm{C} 61.18 ; \mathrm{H}$ 4.04 .

\subsection{Allyl $[2,3,5$-tri- $O$-benzoyl- $\alpha$-D-arabinofuranosyl-} $(1 \rightarrow 2)$-3,4,6-tri- $O$-benzoyl- $\alpha$-D-mannopyranosyl$(1 \rightarrow 2)$-3,4,6-tri- $O$-benzoyl- $\alpha$-D-mannopyranosyl-( $(1 \rightarrow 6)$ $[2,3,4,6$-tetra- $O$-benzoyl- $\alpha$-D-mannopyranosyl-(12)]-3,4di- $O$-benzoyl- $\alpha$-D-mannopyranoside (19)

As described in the general procedure, $13(235 \mathrm{mg}$, $0.16 \mathrm{mmol})$ and 18 (206 $\mathrm{mg}, 0.19 \mathrm{mmol})$ were coupled, and the product was purified by silica gel column chromatography with $1.5: 1$ petroleum ether-EtOAc as the eluent to give $19(310 \mathrm{mg}, 81.5 \%)$ as a foamy solid: $[\alpha]_{\mathrm{D}}-34.7\left(c\right.$ 1.0, $\left.\mathrm{CHCl}_{3}\right) ;{ }^{1} \mathrm{H}$ NMR $\left(400 \mathrm{MHz}, \mathrm{CDCl}_{3}\right)$ : $\delta$ 8.09-6.95 (m, 75H, 15Ph), 6.14-5.83 (m, 10H, Manp $\left.\mathrm{H}-2,4 \mathrm{H}-3,4 \mathrm{H}-4,-\mathrm{CH}_{2}-\mathrm{CH}=\mathrm{CH}_{2}\right), 5.54(\mathrm{~s}, 1 \mathrm{H}$, Araf $\mathrm{H}-$ 2), $5.53\left(\mathrm{~d}, 1 \mathrm{H}, J_{3.4}=4.3 \mathrm{~Hz}\right.$, Araf $\left.\mathrm{H}-3\right), 5.45-5.28(\mathrm{~m}$, $\left.2 \mathrm{H},-\mathrm{CH}_{2}-\mathrm{CH}=\mathrm{CH}_{2}\right), 5.32(\mathrm{~s}, 1 \mathrm{H}$, Araf $\mathrm{H}-1), 5.28$ (s, $1 \mathrm{H}, \operatorname{Man} p \mathrm{H}-1), 5.22$ (s, 2H, Manp 2H-1), 5.20 (s, H, Man $p$ H-1), 4.75-3.64 (m, 20H, Manp 3H-2, 4H-5, 8H6, Araf $\left.\mathrm{H}-4,2 \mathrm{H}-5, \quad-\mathrm{CH}_{2}-\mathrm{CH}=\mathrm{CH}_{2}\right) ;{ }^{13} \mathrm{C} \quad \mathrm{NMR}$ $\left(100 \mathrm{MHz}, \mathrm{CDCl}_{3}\right): \delta 166.19,166.07,165.98,165.86$, $165.66,165.65,165.57,165.54,165.34,165.31,165.28$, 165.23, 164.85, 164.83, 164.78 (PhCO), 106.87 (Araf C1), 100.86, 99.46, 98.63, 97.98 (C-1), 81.90, 81.77, 76.26, $75.45,71.74,71.26,70.90,70.19,69.80,69.74,69.64$, $68.68,68.65,67.59,67.54,66.91,66.73,63.77,63.51$, 63.11, 62.97. Anal. Calcd for $\mathrm{C}_{137} \mathrm{H}_{114} \mathrm{O}_{40}$ : C 68.55; $\mathrm{H}$ 4.79. Found: C 68.37; H 5.70.

3.15. Allyl [ $\alpha$-D-arabinofuranosyl-( $1 \rightarrow 2)-\alpha$-D-mannopyranosyl-(1 $\rightarrow 2)]-\alpha$-D-mannopyranosyl-( $1 \rightarrow 6)$-[ $\alpha$-D-manno-

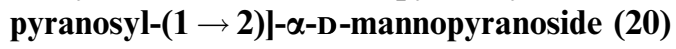

Pentasaccharide 19 (299 mg, $0.13 \mathrm{mmol}$ ) was dissolved in satd $\mathrm{NH}_{3}-\mathrm{MeOH}(60 \mathrm{~mL})$. After $96 \mathrm{~h}$ at $\mathrm{rt}$, the reaction mixture was concentrated, and the residue was purified 
by chromatography on Sephadex LH-20 (MeOH) to afford $30(95 \mathrm{mg}, 91.0 \%)$ as a foamy solid: $[\alpha]_{\mathrm{D}}+78.5(c$ $\left.1.0, \mathrm{H}_{2} \mathrm{O}\right) ;{ }^{1} \mathrm{H}$ NMR $\left(400 \mathrm{MHz}, \mathrm{D}_{2} \mathrm{O}\right): \delta 5.89-5.79(\mathrm{~m}$, $\left.1 \mathrm{H},-\mathrm{CH}_{2}-\mathrm{CH}=\mathrm{CH}_{2}\right), 5.24\left(\mathrm{~d}, 1 \mathrm{H}, J=17.2 \mathrm{~Hz},-\mathrm{CH}_{2}-\right.$ $\left.\mathrm{C} H=\mathrm{CH}_{\text {trans }}\right), \quad 5.16 \quad\left(\mathrm{~d}, \quad 1 \mathrm{H}, \quad J=10.4 \mathrm{~Hz}, \quad-\mathrm{CH}_{2}-\right.$ $\left.\mathrm{CH}=\mathrm{CH}_{c i s}\right), 5.06(\mathrm{~s}, 1 \mathrm{H}, \operatorname{Man} p \mathrm{H}-1), 5.05(\mathrm{~s}, 1 \mathrm{H}$, Araf $\mathrm{H}-1$ ), 5.01 (s, 1H, Manp H-1), 4.99 (s, 1H, Manp H-1), 4.89 (s, 1H, Man $p \mathrm{H}-1) ;{ }^{13} \mathrm{C}$ NMR $\left(100 \mathrm{MHz}, \mathrm{D}_{2} \mathrm{O}\right): \delta$ 109.36 (Ara $f$ C-1) , 102.32, 101.36, 97.95, 97.47 (Man $p$ C1), 83.62, 81.19, 78.85, 78.67, 77.43, 76.44, 73.31, 73.15, $72.82,71.07,70.47,70.38,70.08,70.04,68.42,66.98$, $66.81,66.75,66.69,65.66,61.15,61.06,60.91$. Anal. Calcd for $\mathrm{C}_{32} \mathrm{H}_{54} \mathrm{O}_{25}$ : C 45.82; H 6.49. Found: C 46.01; H 6.55 .

\subsection{Allyl 2- $O$-acetyl-3,4,6-tri- $O$-benzoyl- $\alpha$-D-manno- pyranosyl-(1 $\rightarrow 6)$-3,4-di- $O$-benzoyl-2-O-chloroacetyl- $\alpha$ - D-mannopyranosyl-( $(\rightarrow 6)$-2- $O$-acetyl-3- $O$-benzoyl- $\alpha$-D- mannopyranoside (21)}

Donor 10 (411 mg, $0.37 \mathrm{mmol})$ was coupled with acceptor $4(160 \mathrm{mg}, 0.44 \mathrm{mmol})$ as described in the general procedure, and the product was purified by chromatography with $2: 1$ petroleum ether-EtOAc as the eluent to give $21(410 \mathrm{mg}, 84.5 \%)$ as a foamy solid: $[\alpha]_{D}$ +42.7 (c 0.6, $\left.\mathrm{CHCl}_{3}\right) ;{ }^{1} \mathrm{H}$ NMR $\left(400 \mathrm{MHz}, \mathrm{CDCl}_{3}\right): \delta$ 8.03-7.26 (m, 30H, 6Ph), 5.98-5.88 (m, $1 \mathrm{H},-\mathrm{CH}_{2}-$ $\left.\mathrm{C} H=\mathrm{CH}_{2}\right), 5.91\left(\mathrm{dd}, 1 \mathrm{H}, J_{3^{\prime \prime}, 4^{\prime \prime}}=J_{4^{\prime \prime}, 5^{\prime \prime}}=10.1 \mathrm{~Hz}, \mathrm{H}-\right.$ $\left.4^{\prime \prime}\right), 5.90\left(\mathrm{dd}, 2 \mathrm{H}, J_{2^{\prime \prime}} 3^{\prime \prime}=J_{2^{\prime}, 3^{\prime}}=3.3 \mathrm{~Hz}, J_{3^{\prime \prime}, 4^{\prime \prime}}=J_{3^{\prime}, 4^{\prime}}=\right.$ $\left.10.1 \mathrm{~Hz}, \mathrm{H}-3^{\prime \prime}, \quad \mathrm{H}-3^{\prime \prime}\right), 5.85\left(\mathrm{dd}, 1 \mathrm{H}, J_{3^{\prime}, 4^{\prime}}=J_{4^{\prime}, 5^{\prime}}=\right.$ $\left.10.1 \mathrm{~Hz}, \quad \mathrm{H}-4^{\prime}\right), \quad 5.66 \quad\left(\mathrm{dd}, \quad 1 \mathrm{H}, \quad J_{1^{\prime \prime}, 2^{\prime \prime}}=1.6 \mathrm{~Hz}\right.$, $\left.J_{2^{\prime \prime} .3^{\prime \prime}}=3.3 \mathrm{~Hz}, \quad \mathrm{H}-2^{\prime \prime}\right), \quad 5.54\left(\mathrm{dd}, 1 \mathrm{H}, J_{2,3}=3.4 \mathrm{~Hz}\right.$, $\left.J_{3,4}=9.9 \mathrm{~Hz}, \quad \mathrm{H}-3\right), \quad 5.52\left(\mathrm{dd}, \quad 1 \mathrm{H}, \quad J_{1^{\prime}, 2^{\prime}}=1.6 \mathrm{~Hz}\right.$, $\left.J_{2^{\prime}, 3^{\prime}}=3.3 \mathrm{~Hz}, \quad \mathrm{H}-2^{\prime}\right), \quad 5.44\left(\mathrm{dd}, \quad 1 \mathrm{H}, \quad J_{1,2}=1.7 \mathrm{~Hz}\right.$, $\left.J_{2,3}=3.4 \mathrm{~Hz}, \mathrm{H}-2\right), 5.39-5.21\left(\mathrm{~m}, 2 \mathrm{H},-\mathrm{CH}_{2}-\mathrm{CH}=\mathrm{CH}_{2}\right)$, $5.17\left(\mathrm{~d}, 1 \mathrm{H}, J_{1^{\prime \prime} .2^{\prime \prime}}=1.6 \mathrm{~Hz}, \mathrm{H}-1^{\prime \prime}\right), 5.02(\mathrm{~d}, 1 \mathrm{H}$, $\left.J_{1^{\prime}, 2^{\prime}}=1.6 \mathrm{~Hz}, \mathrm{H}-1^{\prime}\right), 4.97\left(\mathrm{~d}, 1 \mathrm{H}, J_{1,2}=1.7 \mathrm{~Hz}, \mathrm{H}-1\right)$, 4.52-3.72 (m, 14H, H-4, 3H-5, 6H-6, $-\mathrm{CH}_{2}-\mathrm{CH}=\mathrm{CH}_{2}$, $\mathrm{CH}_{2} \mathrm{ClCO}$ ), 2.16 (s, 3H, $\left.\mathrm{CH}_{3} \mathrm{CO}\right), 2.12$ (s, $3 \mathrm{H}, \mathrm{CH}_{3} \mathrm{CO}$ ). Anal. Calcd for $\mathrm{C}_{69} \mathrm{H}_{65} \mathrm{ClO}_{25}$ : C 62.33; H 4.93. Found: C 62.13; H 4.95 .

\subsection{Allyl 2-O-acetyl-3,4,6-tri- $O$-benzoyl- $\alpha$-D-manno- pyranosyl-(1 $\rightarrow 6)$-3,4-di- $O$-benzoyl-2-O-chloroacetyl- $\alpha$ - D-mannopyranosyl-(1 $\rightarrow$ 6)-2-O-acetyl-3,4-di- $O$-benzoyl- $\alpha$-D-mannopyranoside (22)}

Compound 21 ( $395 \mathrm{mg}, 0.3 \mathrm{mmol}$ ) was benzoylated under the same conditions as those used for preparation of 7 from 6, giving a residue that was purified by flash chromatography (2.5:1 petroleum ether-EtOAc) to furnish $22(380 \mathrm{mg}, 89.2 \%)$ as a foamy solid: $[\alpha]_{\mathrm{D}}+44.6$ (c 1.0, $\left.\mathrm{CHCl}_{3}\right) ;{ }^{1} \mathrm{H}$ NMR $\left(400 \mathrm{MHz}, \mathrm{CDCl}_{3}\right): \delta 7.98$ $7.26(\mathrm{~m}, 35 \mathrm{H}, 7 P h), 6.02-5.83(\mathrm{~m}, 7 \mathrm{H}, 3 \mathrm{H}-3,3 \mathrm{H}-4$, $\left.-\mathrm{CH}_{2}-\mathrm{CH}=\mathrm{CH}_{2}\right), 6.02-5.91\left(\mathrm{~m}, 1 \mathrm{H},-\mathrm{CH}_{2}-\mathrm{CH}=\mathrm{CH}_{2}\right)$, $5.99\left(\mathrm{dd}, 1 \mathrm{H}, J_{3^{\prime \prime}, 4^{\prime \prime}}=J_{4^{\prime \prime}, 5^{\prime \prime}}=10.9 \mathrm{~Hz}, \mathrm{H}-4^{\prime \prime}\right), 5.98(\mathrm{dd}$, $\left.1 \mathrm{H}, \quad J_{3^{\prime}, 4^{\prime}}=J_{4^{\prime}, 5^{\prime}}=10.2 \mathrm{~Hz}, \quad \mathrm{H}-4^{\prime}\right) \quad 5.92 \quad(\mathrm{dd}, \quad 1 \mathrm{H}$, $\left.J_{3,4}=J_{4,5}=9.9 \mathrm{~Hz}, \mathrm{H}-4\right), 5.91\left(\mathrm{dd}, 1 \mathrm{H}, J_{2^{\prime \prime}, 3^{\prime \prime}}=3.0 \mathrm{~Hz}\right.$, $\left.J_{3^{\prime \prime}, 4^{\prime \prime}}=10.9 \mathrm{~Hz}, \mathrm{H}-3^{\prime \prime}\right), 5.85\left(\mathrm{dd}, 1 \mathrm{H}, J_{2^{\prime}, 3^{\prime}}=3.0 \mathrm{~Hz}\right.$, $\left.J_{3^{\prime}, 4^{\prime}}=10.2 \mathrm{~Hz}, \quad \mathrm{H}-3^{\prime}\right), 5.84\left(\mathrm{dd}, 1 \mathrm{H}, J_{2,3}=3.1 \mathrm{~Hz}\right.$, $\left.J_{3,4}=9.9 \mathrm{~Hz}, \quad \mathrm{H}-3\right), \quad 5.65\left(\mathrm{dd}, \quad 1 \mathrm{H}, \quad J_{1^{\prime \prime}, 2^{\prime \prime}}=1.2 \mathrm{~Hz}\right.$, $\left.J_{2^{\prime \prime}, 3^{\prime \prime}}=3.0 \mathrm{~Hz}, \mathrm{H}-2\right), \quad 5.54\left(\mathrm{dd}, 1 \mathrm{H}, J_{1^{\prime}, 2^{\prime}}=1.2 \mathrm{~Hz}\right.$, $\left.J_{2^{\prime}, 3^{\prime}}=3.0 \mathrm{~Hz}, \quad \mathrm{H}-2\right), \quad 5.48 \quad\left(\mathrm{dd}, \quad 1 \mathrm{H}, \quad J_{1,2}=1.3 \mathrm{~Hz}\right.$, $\left.J_{2,3}=3.1 \mathrm{~Hz}, \quad \mathrm{H}-2\right), \quad 5.45-5.27 \quad\left(\mathrm{~m}, \quad 2 \mathrm{H}, \quad-\mathrm{CH}_{2}\right.$ $\left.\mathrm{CH}=\mathrm{CH}_{2}\right), 5.07\left(\mathrm{~d}, 1 \mathrm{H}, J_{1^{\prime \prime}, 2^{\prime \prime}}=1.2 \mathrm{~Hz}, \mathrm{H}-1^{\prime \prime}\right), 5.05(\mathrm{~d}$, $\left.1 \mathrm{H}, J_{1^{\prime}, 2^{\prime}}=1.2 \mathrm{~Hz}, \mathrm{H}-1^{\prime}\right), 4.88\left(\mathrm{~d}, 1 \mathrm{H}, J_{1,2}=1.3 \mathrm{~Hz}, \mathrm{H}-\right.$ 1), 4.46-3.49 (m, $13 \mathrm{H}, 3 \mathrm{H}-5,6 \mathrm{H}-6,-\mathrm{CH}_{2}-\mathrm{CH}=\mathrm{CH}_{2}$, $\mathrm{CH}_{2} \mathrm{ClCO}$ ), 2.20 (s, 3H, $\mathrm{CH}_{3} \mathrm{CO}$ ), 2.11 (s, 3H, $\mathrm{CH}_{3} \mathrm{CO}$ ); ${ }^{13} \mathrm{C}$ NMR $\left(100 \mathrm{MHz}, \mathrm{CDCl}_{3}\right): \quad \delta \quad 170.26, \quad 169.65$ $\left(\mathrm{CH}_{3} \mathrm{CO}\right), \quad 166.78, \quad 165.96,165.48,165.43,165.33$, 165.28, 165.18 (PhCO), 97.55, 97.37, 96.73 (C-1), 71.34, $70.19,69.90,69.89,69.79,69.69,69.68,68.86,68.75$, 66.67, 66.62, 66.51, 66.14, 65.67, 62.92, 40.74, 20.76, 20.68. Anal. Calcd for $\mathrm{C}_{76} \mathrm{H}_{69} \mathrm{ClO}_{26}$ : C 63.66; H 4.85. Found: C 63.48; H 4.92.

3.18. 2- $O$-Acetyl-3,4,6-tri- $O$-benzoyl- $\alpha$-D-mannopyranosyl-( $1 \rightarrow 6)-3,4-$ di- $O$-benzoyl-2- $O$-chloroacetyl- $\alpha-\mathrm{D}-$ mannopyranosyl-( $1 \rightarrow 6)$-2- $O$-acetyl-3,4-di- $O$-benzoyl- $\alpha$ D-mannopyranosyl trichloroacetimidate (24)

Deallylation of trisaccharide $22(365 \mathrm{mg}, 0.25 \mathrm{mmol})$, followed by trichloroacetimidation under the same conditions as those used for preparation of $\mathbf{1 0}$ from $\mathbf{7}$, gave a residue that was purified by flash chromatography (3:1 petroleum ether-EtOAc) to give $24(292 \mathrm{mg}$, $74.7 \%$ for two steps) as a foamy solid: $[\alpha]_{\mathrm{D}}+50.6(c 1.5$, $\left.\mathrm{CHCl}_{3}\right) ;{ }^{1} \mathrm{H}$ NMR $\left(400 \mathrm{MHz}, \mathrm{CDCl}_{3}\right): \delta 8.94(\mathrm{~s}, 1 \mathrm{H}$, $\left.\mathrm{CNHCCl}_{3}\right), 8.05-7.26(\mathrm{~m}, 35 \mathrm{H}, 7 \mathrm{Ph}), 6.44(\mathrm{~s}, 1 \mathrm{H}, \mathrm{H}-1)$, $6.10\left(\mathrm{dd}, 1 \mathrm{H}, J_{3^{\prime \prime}, 4^{\prime \prime}}=J_{4^{\prime \prime}}, 5^{\prime \prime}=10.2 \mathrm{~Hz}, \mathrm{H}-4^{\prime \prime}\right), 5.96-5.75$ (m, 5H, H-3", H-3', H-3, H-4', H-4), 5.75 (s, 1H, H-2"), $5.61\left(\mathrm{~s}, 1 \mathrm{H}, \mathrm{H}-2^{\prime}\right), 5.37$ (s, 1H, H-2), 5.03 (s, 1H, H-1"), $4.86\left(\mathrm{~s}, 1 \mathrm{H}, \mathrm{H}-1^{\prime}\right), 4.56-3.49(\mathrm{~m}, 11 \mathrm{H}, 3 \mathrm{H}-5,6 \mathrm{H}-6$, $\mathrm{CH}_{2} \mathrm{ClCO}$ ), 2.24 (s, $\left.3 \mathrm{H}, \mathrm{CH}_{3} \mathrm{CO}\right), 2.09$ (s, $3 \mathrm{H}, \mathrm{CH}_{3} \mathrm{CO}$ ). Anal. Calcd for $\mathrm{C}_{75} \mathrm{H}_{65} \mathrm{Cl}_{4} \mathrm{NO}_{26}$ : C 58.57; $\mathrm{H} 4.26$. Found: C 58.33; H 4.18.

3.19. Allyl 2- $O$-acetyl-3,4,6-tri- $O$-benzoyl- $\alpha$-D-mannopyranosyl-( $1 \rightarrow 6$ )-3,4-di- $O$-benzoyl-2- $O$-chloroacetyl- $\alpha$ D-mannopyranosyl-(1 $\rightarrow 6)-2-O$-acetyl-3,4-di- $O$-benzoyl$\alpha$-D-mannopyranosyl-( $1 \rightarrow$ ) $)$-3- $O$-benzoyl-2- $O$-chloroacetyl- $\alpha$-D-mannopyranoside (25)

Donor $24(277 \mathrm{mg}, 0.18 \mathrm{mmol})$ was coupled with acceptor $3(87 \mathrm{mg}, 0.22 \mathrm{mmol})$ as described in the general procedure to give a crude product that was purified by flash chromatography $(1.5: 1$ petroleum etherEtOAc) to give $25(256 \mathrm{mg}, 80.1 \%)$ as a foamy solid: $[\alpha]_{\mathrm{D}}$ +50.2 (c 1.0, $\left.\mathrm{CHCl}_{3}\right) ;{ }^{1} \mathrm{H} \mathrm{NMR}\left(400 \mathrm{MHz}, \mathrm{CDCl}_{3}\right): \delta$ $8.00-7.26(\mathrm{~m}, 40 \mathrm{H}, 8 P h), 6.00\left(\mathrm{dd}, 1 \mathrm{H}, J_{3^{\prime \prime \prime} \cdot 4^{\prime \prime \prime}}=\right.$ $\left.J_{4^{\prime \prime \prime}, 5^{\prime \prime \prime}}=10.0 \mathrm{~Hz}, \mathrm{H}-4^{\prime \prime \prime}\right), 5.96-5.81$ (m, 6H, H-3 $3^{\prime \prime \prime}, \stackrel{4}{\mathrm{H}-} 3^{\prime \prime}$, $\left.\mathrm{H}-3^{\prime}, \quad \mathrm{H}-4^{\prime \prime}, \quad \mathrm{H}-4^{\prime}, \quad-\mathrm{CH}_{2}-\mathrm{CH}=\mathrm{CH}_{2}\right), 5.63(\mathrm{dd}, 1 \mathrm{H}$, 
$\left.J_{1^{\prime \prime \prime}, 2^{\prime \prime \prime}}=1.4 \mathrm{~Hz}, J_{2^{\prime \prime \prime}, 3^{\prime \prime \prime}}=3.2 \mathrm{~Hz}, \mathrm{H}-2^{\prime \prime \prime}\right), 5.58(\mathrm{dd}, 1 \mathrm{H}$, $\left.J_{2,3}=3.2 \mathrm{~Hz}, \quad J_{3,4}=10.0 \mathrm{~Hz}, \quad \mathrm{H}-3\right), 5.57 \quad(\mathrm{dd}, \quad 1 \mathrm{H}$, $\left.J_{1^{\prime \prime}, 2^{\prime \prime}}=1.6 \mathrm{~Hz}, J_{2^{\prime \prime}, 3^{\prime \prime}}=3.2 \mathrm{~Hz}, \mathrm{H}-2^{\prime \prime}\right), 5.52(\mathrm{dd}, 1 \mathrm{H}$, $\left.J_{1^{\prime}, 2^{\prime}}=1.6 \mathrm{~Hz}, \quad J_{2^{\prime}, 3^{\prime}}=3.2 \mathrm{~Hz}, \mathrm{H}-2^{\prime}\right), 5.49 \quad(\mathrm{dd}, 1 \mathrm{H}$, $\left.J_{1,2}=1.6 \mathrm{~Hz}, J_{2,3}=3.2 \mathrm{~Hz}, \mathrm{H}-2\right), 5.39-5.22(\mathrm{~m}, 2 \mathrm{H}$, $\left.-\mathrm{CH}_{2}-\mathrm{CH}=\mathrm{CH}_{2}\right), 5.18\left(\mathrm{~d}, 1 \mathrm{H}, J_{1^{\prime \prime \prime}, 2^{\prime \prime \prime}}=1.4 \mathrm{~Hz}, \mathrm{H}-1^{\prime \prime \prime}\right)$, $5.06\left(\mathrm{~d}, 1 \mathrm{H}, J_{1^{\prime \prime} .2^{\prime \prime}}=1.6 \mathrm{~Hz}, \mathrm{H}-1^{\prime \prime}\right), 5.00(\mathrm{~d}, 1 \mathrm{H}$, $\left.J_{1^{\prime}, 2^{\prime}}=1.6 \mathrm{~Hz}, \mathrm{H}-1^{\prime}\right), 4.92\left(\mathrm{~d}, 1 \mathrm{H}, J_{1,2}=1.6 \mathrm{~Hz}, \mathrm{H}-1\right)$, 4.48-3.59 (m, 19H, H-4, 4H-5, 8H-6, 2C $\mathrm{H}_{2} \mathrm{ClCO}$, $\left.-\mathrm{CH}_{2}-\mathrm{CH}=\mathrm{CH}_{2}\right), 2.17\left(\mathrm{~s}, 3 \mathrm{H}, \mathrm{CH}_{3} \mathrm{CO}\right), 2.07(\mathrm{~s}, 3 \mathrm{H}$, $\mathrm{CH}_{3} \mathrm{CO}$ ). Anal. Calcd for $\mathrm{C}_{91} \mathrm{H}_{84} \mathrm{Cl}_{2} \mathrm{O}_{33}$ : C 61.52; $\mathrm{H}$ 4.77. Found: C 61.21; H 4.85.

\subsection{Allyl 2-O-acetyl-3,4,6-tri- $O$-benzoyl- $\alpha$-D-manno- pyranosyl-(1 $\rightarrow 6)-3,4-d i-O$-benzoyl-2- $O$-chloroacetyl- $\alpha$ - D-mannopyranosyl-( $\rightarrow$ 6)-2- $O$-acetyl-3,4-di- $O$-benzoyl- $\alpha$-D-mannopyranosyl-( $\rightarrow$ 6)-3,4-di- $O$-benzoyl-2- $O$-chloro-

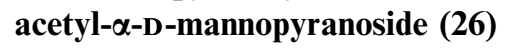

Compound 25 (242 mg, $0.14 \mathrm{mmol}$ ) was benzoylated under the same conditions as those used for preparation of 7 from 6, giving a residue that was purified by flash chromatography $(2.5: 1$ petroleum ether-EtOAc) to furnish $26(219 \mathrm{mg}, 85.5 \%)$ as a foamy solid: $[\alpha]_{\mathrm{D}}+46.6$ (c 1.0, $\left.\mathrm{CHCl}_{3}\right) ;{ }^{1} \mathrm{H}$ NMR $\left(400 \mathrm{MHz}, \mathrm{CDCl}_{3}\right): \delta 8.08-$ $7.26(\mathrm{~m}, 45 \mathrm{H}, 9 P h), 6.10-5.81(\mathrm{~m}, 9 \mathrm{H}, 4 \mathrm{H}-3,4 \mathrm{H}-4$, $\left.-\mathrm{CH}_{2}-\mathrm{CH}=\mathrm{CH}_{2}\right), \quad 5.65 \quad\left(\mathrm{dd}, \quad 1 \mathrm{H}, \quad J_{1^{\prime \prime \prime}, 2^{\prime \prime \prime}}=1.4 \mathrm{~Hz}\right.$, $\left.J_{2^{\prime \prime \prime}, 3^{\prime \prime \prime}}=3.2 \mathrm{~Hz}, \mathrm{H}-2^{\prime \prime \prime}\right), 5.59\left(\mathrm{dd}, 1 \mathrm{H}, J_{1^{\prime \prime}, 2^{\prime \prime}}=1.4 \mathrm{~Hz}\right.$, $\left.J_{2^{\prime \prime}, 3^{\prime \prime}}=3.2 \mathrm{~Hz}, \quad \mathrm{H}-2^{\prime \prime}\right), 5.57\left(\mathrm{dd}, 1 \mathrm{H}, J_{1^{\prime}, 2^{\prime}}=1.6 \mathrm{~Hz}\right.$, $\left.J_{2^{\prime}, 3^{\prime}}=3.2 \mathrm{~Hz}, \quad \mathrm{H}-2^{\prime}\right), \quad 5.43-5.26 \quad\left(\mathrm{~m}, \quad 2 \mathrm{H}, \quad-\mathrm{CH}_{2}-\right.$ $\left.\mathrm{CH}=\mathrm{CH}_{2}\right), 5.40\left(\mathrm{dd}, 1 \mathrm{H}, J_{1,2}=1.6 \mathrm{~Hz}, J_{2,3}=3.2 \mathrm{~Hz}, \mathrm{H}-\right.$ 2), $5.09\left(\mathrm{~d}, 2 \mathrm{H}, J_{1^{\prime \prime \prime}, 2^{\prime \prime \prime}}=J_{1^{\prime \prime}, 2^{\prime \prime}}=1.4 \mathrm{~Hz}, \mathrm{H}-1^{\prime \prime \prime}, \mathrm{H}-1^{\prime \prime}\right)$, $4.93\left(\mathrm{~d}, 1 \mathrm{H}, \quad J_{1^{\prime}, 2^{\prime}}=1.6 \mathrm{~Hz}, \mathrm{H}-1^{\prime}\right), 4.87(\mathrm{~d}, 1 \mathrm{H}$, $\left.J_{1,2}=1.6 \mathrm{~Hz}, \mathrm{H}-1\right), 4.41-3.48(\mathrm{~m}, 18 \mathrm{H}, 4 \mathrm{H}-5,8 \mathrm{H}-6$, $\left.2 \mathrm{CH}_{2} \mathrm{ClCO},-\mathrm{CH}_{2}-\mathrm{CH}=\mathrm{CH}_{2}\right), 2.18\left(\mathrm{~s}, 3 \mathrm{H}, \mathrm{CH}_{3} \mathrm{CO}\right)$, 2.09 (s, 3H, CH $\mathrm{CH}_{3} \mathrm{CO} ;{ }^{13} \mathrm{C} \mathrm{NMR}\left(100 \mathrm{MHz}, \mathrm{CDCl}_{3}\right): \delta$ $170.13,169.68\left(\mathrm{CH}_{3} \mathrm{CO}\right), 166.69,166.79\left(\mathrm{CH}_{2} \mathrm{ClCO}\right)$, 165.94, 165.50, 165.49, 165.46, 165.34, 165.32, 165.30, 165.25, 165.23 (PhCO), 97.89, 97.86, 97.16, 96.29 (C-1), $71.62,71.29,70.17,70.12,70.03,69.89,69.83,69.71$, $69.66,68.88,68.82,66.61,66.56,66.20,66.13,66.06$, 65.93, 65.69, 62.87, 40.80, 20.72, 20.68. Anal. Calcd for $\mathrm{C}_{98} \mathrm{H}_{88} \mathrm{Cl}_{2} \mathrm{O}_{34}$ : C 68.59; $\mathrm{H}$ 4.72. Found: C 68.88; H 4.66.

3.21. Allyl 2-O-acetyl-3,4,6-tri- $O$-benzoyl- $\alpha$-D-mannopyranosyl-( $1 \rightarrow 6)$-3,4-di- $O$-benzoyl- $\alpha$-D-mannopyranosyl-(1 $\rightarrow$ 6)-2- $O$-acetyl-3,4-di- $O$-benzoyl- $\alpha$-D-mannopyranosyl-( $1 \rightarrow 6)-3$,4-di- $O$-benzoyl- $\alpha$-D-mannopyranoside (27)

Dechloroacetylation of $\mathbf{2 6}$ (208 $\mathrm{mg}, 0.1 \mathrm{mmol})$ using the same conditions as those used for preparation of $\mathbf{8}$ from 7 gave a residue that was purified by flash chromatography (2:1 petroleum ether-EtOAc) to furnish 27 $(157 \mathrm{mg}, 82.3 \%)$ as a foamy solid: $[\alpha]_{\mathrm{D}}+37.5$ (c 1.0, $\left.\mathrm{CHCl}_{3}\right) ;{ }^{1} \mathrm{H}$ NMR $\left(400 \mathrm{MHz}, \mathrm{CDCl}_{3}\right): \delta 8.10-7.23(\mathrm{~m}$,
$45 \mathrm{H}, 9 P h), 6.14-6.06\left(\mathrm{~m}, 2 \mathrm{H}, \mathrm{H}-4^{\prime \prime \prime},-\mathrm{CH}_{2}-\mathrm{CH}=\mathrm{CH}_{2}\right)$, 5.70-5.96 (m, 7H, 4H-3, 3H-4), 5.55-5.33 (m, 2H, $\left.\mathrm{CH}_{2}-\mathrm{CH}=\mathrm{CH}_{2}\right), 5.52-5.50\left(\mathrm{~m}, 2 \mathrm{H}, \mathrm{H}-2^{\prime}, \mathrm{H}-2^{\prime \prime \prime}\right), 5.21(\mathrm{~d}$, $\left.2 \mathrm{H}, J_{1^{\prime \prime \prime}, 2^{\prime \prime \prime}}=J_{1^{\prime \prime}, 2^{\prime \prime}}=1.4 \mathrm{~Hz}, \mathrm{H}-1^{\prime \prime \prime}, \mathrm{H}-1^{\prime \prime}\right), 5.03(\mathrm{~d}, 1 \mathrm{H}$, $\left.J_{1^{\prime}, 2^{\prime}}=1.5 \mathrm{~Hz}, \mathrm{H}^{\prime} 1^{\prime}\right), 4.91\left(\mathrm{~d}, 1 \mathrm{H}, J_{1,2}=1.6 \mathrm{~Hz}, \mathrm{H}-1\right)$, $4.72-3.50 \quad\left(\mathrm{~m}, \quad 16 \mathrm{H}, \quad 2 \mathrm{H}-2, \quad 4 \mathrm{H}-5, \quad 8 \mathrm{H}-6, \quad-\mathrm{CH}_{2}-\right.$ $\left.\mathrm{CH}=\mathrm{CH}_{2}\right), 2.15$ (s, 3H, $\left.\mathrm{CH}_{3} \mathrm{CO}\right), 2.10$ (s, 3H, $\left.\mathrm{CH}_{3} \mathrm{CO}\right)$; ${ }^{13} \mathrm{C} \quad \mathrm{NMR} \quad\left(100 \mathrm{MHz}, \mathrm{CDCl}_{3}\right): \delta \quad 170.09, \quad 169.75$ $\left(\mathrm{CH}_{3} \mathrm{CO}\right), \quad 166.04,166.01,165.73,165.64,165.61$, 165.59, 165.58, 165.57, 165.34 (PhCO), 98.80, 98.68, 97.75, 96.74 (C-1), 72.94, 72.58, 70.24, 70.04, 69.97, $69.85,69.78,69.49,69.14,68.75,68.72,68.27,67.70$, 67.07, 66.83, 66.74, 66.41, 66.35, 66.29, 20.80, 20.73. Anal. Calcd for $\mathrm{C}_{94} \mathrm{H}_{86} \mathrm{O}_{32}$ : C 65.35; H 5.02. Found: $\mathrm{C}$ 65.07; H 4.98.

3.22. Allyl 2-O-acetyl-3,4,6-tri- $O$-benzoyl- $\alpha$-D-mannopyranosyl-( $1 \rightarrow 6)-[2,3,4,6$-tetra- $O$-benzoyl- $\alpha$-D-mannopyranosyl-(1 $\rightarrow 2)$ ]-3,4-di- $O$-benzoyl- $\alpha$-D-mannopyranosyl-(1 $\rightarrow 6)-2-O$-acetyl-3,4-di- $O$-benzoyl- $\alpha$-D-mannopyranosyl-( $1 \rightarrow 6)-[2,3,4,6$-tetra- $O$-benzoyl- $\alpha$-D-mannopyranosyl-( $1 \rightarrow 2)$ ]-3,4-di- $O$-benzoyl- $\alpha$-D-mannopyranoside (28)

Donor 11 (184 mg, $0.25 \mathrm{mmol})$ was coupled with acceptor 27 (143 $\mathrm{mg}, 0.08 \mathrm{mmol})$ as described in the general procedure, and the product was purified by chromatography with 3:2 petroleum ether-EtOAc as the eluent to give $\mathbf{2 8}(205 \mathrm{mg}, 85.9 \%)$ as a foamy solid: $[\alpha]_{\mathrm{D}}$ -18.7 (c 1.0, $\left.\mathrm{CHCl}_{3}\right)$; ${ }^{1} \mathrm{H}$ NMR $\left(400 \mathrm{MHz}, \mathrm{CDCl}_{3}\right): \delta$ 8.16-6.81 (m, 85H, 17Ph), 6.28-5.90 (m, 15H, 2H-2, 6H$\left.3,6 \mathrm{H}-4,-\mathrm{CH}_{2}-\mathrm{CH}=\mathrm{CH}_{2}\right), 5.77\left(\mathrm{~s}, 1 \mathrm{H}, \mathrm{H}-2^{\prime \prime \prime}\right), 5.70(\mathrm{~s}$, $\left.1 \mathrm{H}, \mathrm{H}-2^{\prime}\right), 5.48-5.29\left(\mathrm{~m}, 2 \mathrm{H},-\mathrm{CH}_{2}-\mathrm{CH}=\mathrm{CH}_{2}\right), 5.34(\mathrm{~s}$, $2 \mathrm{H}, \mathrm{H}-1^{\prime \prime \prime}, \mathrm{H}-1^{\prime \prime}$ ), 5.12 (s, 1H, H-1'), 4.99 (s, 1H, H-1), 4.81-3.54 (m, 22H, 2H-2, 6H-5, 12H-6, - $\mathrm{CH}_{2}-$ $\left.\mathrm{CH}=\mathrm{CH}_{2}\right), 2.10$ (s, 3H, $\left.\mathrm{CH}_{3} \mathrm{CO}\right), 2.02$ (s, 3H, $\left.\mathrm{CH}_{3} \mathrm{CO}\right)$; ${ }^{13} \mathrm{C}$ NMR $\left(100 \mathrm{MHz}, \mathrm{CDCl}_{3}\right): \quad \delta \quad 169.99, \quad 169.50$ $\left(\mathrm{CH}_{3} \mathrm{CO}\right), 166.17,165.99,165.81,165.79,165.73$, 165.54, 165.51, 165.19, 164.90, 164.84, 164.80, 164.77, 164.74, 164.68 (PhCO), 99.93, 99.75, 98.32, 97.96, 97.89, 97.68 (C-1), 71.46, 70.81, 70.70, 70.43, 70.33, 70.19, $70.07,69.96,69.82,69.74,69.33,68.72,68.64,67.10$, $66.99,66.76,66.58,66.46,66.10,65.76,62.93,62.66$, 20.69, 20.65. Anal. Calcd for $\mathrm{C}_{162} \mathrm{H}_{138} \mathrm{O}_{50}: \mathrm{C} 67.45 ; \mathrm{H}$ 4.82. Found: C 67.63; H 4.78.

\subsection{Allyl 3,4,6-tri- $O$-benzoyl- $\alpha$-D-mannopyranosyl-} $(1 \rightarrow 6)-[2,3,4,6$-tetra- $O$-benzoyl- $\alpha$-D-mannopyranosyl$(1 \rightarrow 2)]-3,4-d i-O$-benzoyl- $\alpha$-D-mannopyranosyl-( $1 \rightarrow 6)$ 3,4-di- $O$-benzoyl- $\alpha$-D-mannopyranosyl- $(1 \rightarrow 6)-[2,3,4,6-$ tetra- $O$-benzoyl- $\alpha$-D-mannopyranosyl-(1 $\rightarrow 2) \mid-3,4-d i-O$ benzoyl- $\alpha$-D-mannopyranoside (29)

Deacetylation of compound 28 (193 mg, $0.07 \mathrm{mmol}$ ) was carried out under the same conditions as those used for preparation of $\mathbf{1 3}$ from $\mathbf{1 2}$, giving a crude product that 
was purified by flash chromatography $(2: 1$ petroleum ether-EtOAc) to give $29(144 \mathrm{mg}, 76.8 \%)$ as a foamy solid: $[\alpha]_{\mathrm{D}}+47.3\left(\right.$ c $\left.1.0, \mathrm{CHCl}_{3}\right) ;{ }^{1} \mathrm{H}$ NMR $(400 \mathrm{MHz}$, $\left.\mathrm{CDCl}_{3}\right): \delta 8.07-6.90(\mathrm{~m}, 85 \mathrm{H}, 17 \mathrm{Ph}), 6.37(\mathrm{dd}, 1 \mathrm{H}$, $\left.J_{3,4}=J_{4.5}=9.9 \mathrm{~Hz}, \mathrm{H}-4\right), 6.15-5.76(\mathrm{~m}, 14 \mathrm{H}, 2 \mathrm{H}-2,6 \mathrm{H}-$ $\left.3,5 \mathrm{H}-4,-\mathrm{CH}_{2}-\mathrm{CH}=\mathrm{CH}_{2}\right), 5.48(\mathrm{~s}, 1 \mathrm{H}, \mathrm{H}-1), 5.36(\mathrm{~s}$, $1 \mathrm{H}, \mathrm{H}-1), 5.34-5.15\left(\mathrm{~m}, 2 \mathrm{H},-\mathrm{CH}_{2}-\mathrm{CH}=\mathrm{CH}_{2}\right), 5.30(\mathrm{~s}$, $1 \mathrm{H}, \mathrm{H}-1), 5.24$ (s, 1H, H-1), 5.15 (s, 1H, H-1), 5.04 (s, $1 \mathrm{H}, \mathrm{H}-1), 4.88-3.58(\mathrm{~m}, 24 \mathrm{H}, 4 \mathrm{H}-2,6 \mathrm{H}-5,12 \mathrm{H}-6$, $\left.-\mathrm{CH}_{2}-\mathrm{CH}=\mathrm{CH}_{2}\right) ;{ }^{13} \mathrm{C}$ NMR $\left(100 \mathrm{MHz}, \mathrm{CDCl}_{3}\right): \delta$ $166.17,166.12,166.03,165.95,165.73,165.61,165.51$, $165.48,165.40,165.36,165.08,165.00,164.78,164.69$, $164.60(\mathrm{PhCO}), 100.28,100.05,99.29,97.85,97.82$, 97.54 (C-1), 73.23, 72.72, 71.43, 70.59, 70.26, 69.93, $69.83,69.72,69.63,69.54,69.50,69.20,68.94,68.57$, $68.38,67.17,67.11,66.85,66.79,66.67,66.56,66.52$, $66.25,66.90,65.56,63.66,62.94,62.86,62.69$. Anal. Calcd for $\mathrm{C}_{158} \mathrm{H}_{134} \mathrm{O}_{48}$ : C 67.76; H 4.82. Found: C 67.48; H 4.91 .

\subsection{Allyl [2,3,5-tri- $O$-benzoyl- $\alpha$-D-arabinofuranosyl- $(1 \rightarrow 2)-3,4,6$-tri- $O$-benzoyl- $\alpha$-D-mannopyranosyl- $(1 \rightarrow 2)$ )-3,4,6-tri- $O$-benzoyl- $\alpha$-D-mannopyranosyl- $(1 \rightarrow 6)$-[2,3,4,6-tetra- $O$-benzoyl- $\alpha$-D-mannopyranosyl- $(1 \rightarrow 2)]-3,4-d i-O$-benzoyl- $\alpha$-D-mannopyranosyl-(1 $\rightarrow 6)$ - [2,3,5-tri- $O$-benzoyl- $\alpha$-D-arabinofuranosyl-(1 $\rightarrow 2)-3,4,6-$ tri- $O$-benzoyl- $\alpha$-D-mannopyranosyl-( $1 \rightarrow 2)]-3,4-$ di- $O$ - benzoyl- $\alpha$-D-mannopyranosyl-( $1 \rightarrow 6)-[2,3,4,6$-tetra- $O$ - benzoyl- $\alpha$-D-mannopyranosyl-( $(\rightarrow 2) \mid-3,4-d i-O$-benzoyl- $\alpha$-D-mannopyranoside (30)}

Donor 18 (130 mg, $0.12 \mathrm{mmol})$ was coupled with acceptor $29(130 \mathrm{mg}, 0.05 \mathrm{mmol})$ as described in the general procedure, and the product was purified by chromatography with $3: 2$ petroleum ether-EtOAc as the eluent to give $30(143 \mathrm{mg}, 66.7 \%)$ as a foamy solid: $[\alpha]_{D}$ -13.7 (c 1.0, $\mathrm{CHCl}_{3}$ ); ${ }^{1} \mathrm{H}$ NMR $\left(400 \mathrm{MHz}, \mathrm{CDCl}_{3}\right): \delta$ 8.08-6.50 (m, 145H, 29Ph), 6.38-5.86 (m, 19H, Manp $\left.2 \mathrm{H}-2,8 \mathrm{H}-3,8 \mathrm{H}-4,-\mathrm{CH}_{2}-\mathrm{CH}=\mathrm{CH}_{2}\right), 5.61(\mathrm{~s}, 1 \mathrm{H}$, Araf $\mathrm{H}-2), 5.58$ (s, 1H, Araf H-2), 5.57 (s, 1H, Manp H-1), $5.52\left(\mathrm{~d}, 1 \mathrm{H}, J_{3,4}=4.4 \mathrm{~Hz}\right.$, Araf $\left.\mathrm{H}-3\right), 5.50(\mathrm{~d}, 1 \mathrm{H}$, $J_{3,4}=5.0 \mathrm{~Hz}$, Araf H-3), 5.49 (s, $2 \mathrm{H}$, Araf $\left.2 \mathrm{H}-1\right), 5.46-$ $5.27\left(\mathrm{~m}, 2 \mathrm{H},-\mathrm{CH}_{2}-\mathrm{CH}=\mathrm{CH}_{2}\right), 5.44(\mathrm{~s}, 1 \mathrm{H}, \mathrm{Man} p \mathrm{H}-1)$, 5.34 (s, 1H, Manp H-1), 5.33 (s, 1H, Manp H-1), 5.28 (s, $1 \mathrm{H}, \operatorname{Man} p \mathrm{H}-1), 5.27$ (s, 1H, Manp $\mathrm{H}-1), 5.22(\mathrm{~s}, 1 \mathrm{H}$, Manp H-1), 5.11 (s, 1H, Manp H-1), 5.05 (s, 1H, Manp $\mathrm{H}-2), 4.97$ (s, 1H, Manp H-2), 4.89 (s, 1H, Manp H-2), 4.82-3.47 (m, 35H, Manp 3H-2, 8H-5, 16H-6, Araf $\left.2 \mathrm{H}-4,4 \mathrm{H}-5,-\mathrm{CH}_{2}-\mathrm{CH}=\mathrm{CH}_{2}\right) ;{ }^{13} \mathrm{C}$ NMR $(100 \mathrm{MHz}$, $\left.\mathrm{CDCl}_{3}\right): \delta 166.25,166.13,166.09,166.06,165.95,165.88$, $165.82,165.67,165.65,165.60,165.55,165.50,165.45$, $165.21,165.14,165.07,165.02,164.90,164.81,164.45$, 164.39 (PhCO), 107.17, 106.71 (Araf C-1), 100.72, $100.28,99.99,99.43,99.25,98.05,98.65,98.02$ (C-1), $82.08,81.98,81.75,81.62,76.32,75.96,75.25,74.07$, $72.58,72.36,71.86,71.35,71.07,70.56,70.45,70.25$,
$70.04,69.84,69.70,69.51,69.46,69.37,69.25,68.61$, $68.31,67.80,67.34,67.21,66.92,66.63,66.48,66.37$, 65.35, 64.27, 63.50, 63.31, 63.14, 63.01. Anal. Calcd for $\mathrm{C}_{264} \mathrm{H}_{218} \mathrm{O}_{78}$ : C 68.36; H 4.74. Found: C 68.69; H 4.73.

3.25. Allyl [ $\alpha$-D-arabinofuranosyl-( $1 \rightarrow 2)$ - $\alpha$-D-mannopyranosyl-(1 $\rightarrow 2)]-\alpha$-D-mannopyranosyl-(1 $\rightarrow 6)-[\alpha-D-$ mannopyranosyl-(1 $\rightarrow 2)$ |- $\alpha$-D-mannopyranosyl-(1 $\rightarrow 6)$ [ $\alpha$-D-arabinofuranosyl-(1 $\rightarrow 2)-\alpha$-D-mannopyranosyl$(1 \rightarrow 2)]-\alpha$-D-mannopyranosyl-( $1 \rightarrow 6)$-[ $\alpha$-D-mannopyranosyl-( $1 \rightarrow 2) \mid-\alpha$-D-mannopyranoside (31)

Decasaccharide 30 (133 $\mathrm{mg}, 0.03 \mathrm{mmol})$ was dissolved in satd $\mathrm{NH}_{3}-\mathrm{MeOH}(30 \mathrm{~mL})$. After $96 \mathrm{~h}$ at $\mathrm{rt}$, the reaction mixture was concentrated, and the residue was purified by chromatography on Sephadex LH-20 (MeOH) to afford 31 (43 mg, 92.5\%) as a foamy solid: $[\alpha]_{\mathrm{D}}+64.6(c$ $\left.1.0, \mathrm{H}_{2} \mathrm{O}\right) ;{ }^{1} \mathrm{H}$ NMR $\left(400 \mathrm{MHz}, \mathrm{D}_{2} \mathrm{O}\right): \delta 5.91-5.81(\mathrm{~m}$, $\left.1 \mathrm{H},-\mathrm{CH}_{2}-\mathrm{CH}=\mathrm{CH}_{2}\right), 5.25\left(\mathrm{~d}, 1 \mathrm{H}, J=17.2 \mathrm{~Hz},-\mathrm{CH}_{2}-\right.$ $\left.\mathrm{CH}=\mathrm{CH}_{\text {trans }}\right), \quad 5.18 \quad\left(\mathrm{~d}, \quad 1 \mathrm{H}, \quad J=10.0 \mathrm{~Hz}, \quad-\mathrm{CH}_{2}-\right.$ $\left.\mathrm{C} H=\mathrm{CH}_{c i s}\right), 5.09$ (s, 1H, Man $\left.p \mathrm{H}-1\right), 5.08(\mathrm{~s}, 1 \mathrm{H}, \operatorname{Man} p$ $\mathrm{H}-1), 5.07$ (s, 2H, Araf 2H-1), 5.02 (s, 1H, Manp H-1), 5.01 (s, 1H, Manp H-1), 4.99 (s, 2H, Manp 2H-1), 4.93 (s, 1H, Man $p \mathrm{H}-1), 4.91$ (s, 1H, Manp H-1); ${ }^{13} \mathrm{C}$ NMR $\left(100 \mathrm{MHz}, \mathrm{D}_{2} \mathrm{O}\right): \delta 109.36$ (2C, Araf 2C-1), 102.32, 102.19, 101.32, 101.30, 98.17, 98.03, 97.53 (8C, Manp $8 \mathrm{C}-1), 83.65,83.62,81.20,78.85,78.70,78.55,77.46$, $77.43,76.46,73.33,73.26,73.18,72.85,71.28,71.19$, $71.01,70.64,70.57,70.49,70.44,70.24,70.08,70.04$, $68.44,67.02,66.81,66.75,66.67,66.48,65.75,65.63$, 61.18, 61.15, 61.10, 61.07, 60.94, 60.86. Anal. Calcd for $\mathrm{C}_{61} \mathrm{H}_{102} \mathrm{O}_{49}$ : C 45.24; H 6.35. Found: C 45.13; H 6.33.

\section{Acknowledgements}

This work was supported by The Chinese Academy of Sciences (KZCX3-J-08) and by The National Natural Science Foundation of China (Projects 30070185 and 39970864).

\section{References}

1. Prescott, J. F. Clin. Microbiol. Rev. 1991, 4, 20-34.

2. Mosser, D. M.; Hondalus, M. K. Trends Microbiol. 1996, 4, 29-33.

3. (a) Brennan, P. J.; Nikaido, H. Annu. Rev. Biochem. 1995, 64, 29-63; (b) Daffe, M.; Draper, P. Adv. Microb. Physiol. 1998, 39, 131-203.

4. (a) Chatterjee, D.; Khoo, K.-H. Glycobiology 1998, 8, 113 120; (b) Strohmeier, G. R.; Fenton, M. J. Microb. Infect. 1999, 1, 709-717.

5. Dahl, K. E.; Jshiratsuchi, H.; Hamilton, B. D.; Ellner, J. J.; Toossi, Z. Infect. Immun. 1996, 64, 399-405.

6. Garton, N. J.; Gilleron, M.; Brando, T.; Dan, H.-H.; Giguere, S.; Puzo, G.; Prescott, J. F.; Sutcliffe, I. C. J. Biol. Chem. 2002, 277, 31722-31733. 
7. (a) Zhu, Y.; Kong, F. Synlett 2000, 663-667; (b) Zhu, Y.; Kong, F. Carbohydr. Res. 2001, 332, 1-21.

8. (a) Zhang, J.; Kong, F. Tetrahedron: Asymmetry 2002, 13, 243-252; (b) Kong, F. Curr. Org. Chem. 2003, 7, 841-865.

9. (a) Ma, Z.; Zhang, J.; Kong, F. Tetrahedron: Asymmetry 2003, 14, 2595-2603; (b) Zhang, J.; Ma, Z.; Kong, F. Carbohydr. Res. 2003, 338, 2039-2046; (c) Zhang, J.; Kong, F. Bioorg. Med. Chem. 2003, 11, 4027-4037.
10. Ogawa, T.; Yamamoto, H. Carbohydr. Res. 1985, 137, 7986.

11. Schmidt, R. R.; Kinzy, W. Adv. Carbohydr. Chem. Biochem. 1994, 50, 21-125.

12. (a) Byramova, N. E.; Ovchinnikov, M. V.; Backinowsky, L. V.; Kochetkov Carbohydr. Res. 1983, 124, c8; (b) Zhu, Y.; Kong, F. Chin. J. Chem. 2001, 19, 119-123.

13. Du, Y.; Pan, Q.; Kong, F. Synlett 1999, 1648-1652. 